\title{
Thrombocytopenia-associated mutations in Ser/Thr kinase MASTL deregulate actin cytoskeletal dynamics in platelets
}

\author{
Begoña Hurtado, ${ }^{1,2}$ Marianna Trakala,, ${ }^{1}$ Pilar Ximénez-Embún, ${ }^{3}$ Aicha El Bakkali, ${ }^{1}$ David Partida, ${ }^{1}$ Belén Sanz-Castillo, ${ }^{1}$ \\ Mónica Álvarez-Fernández, ${ }^{1}$ María Maroto, ${ }^{1}$ Ruth Sánchez-Martínez, ${ }^{1}$ Lola Martínez ${ }^{4}$, Javier Muñoz, ${ }^{3}$ \\ Pablo García de Frutos, ${ }^{2}$ and Marcos Malumbres ${ }^{1}$
}

'Cell Division and Cancer Group, Spanish National Cancer Research Centre (CNIO), Madrid, Spain. ²Department of Cell Death and Proliferation, Institut d'Investigacions Biomèdiques de Barcelona-Consejo Superior de Investigaciones Científicas- Institut d'Investigacions Biomèdiques August Pi i Sunyer- (IIBB-CSIC-IDIBAPS), Barcelona, Spain. ${ }^{3}$ ProteoRed - Instituto de Salud Carlos III (ISCIII) and Proteomics Unit, CNIO, Madrid, Spain. ${ }^{4}$ Cytometry Unit, CNIO, Madrid, Spain.

\begin{abstract}
MASTL, a Ser/Thr kinase that inhibits PP2A-B55 complexes during mitosis, is mutated in autosomal dominant thrombocytopenia. However, the connections between the cell-cycle machinery and this human disease remain unexplored. We report here that, whereas Mastl ablation in megakaryocytes prevented proper maturation of these cells, mice carrying the thrombocytopenia-associated mutation developed thrombocytopenia as a consequence of aberrant activation and survival of platelets. Activation of mutant platelets was characterized by hyperstabilized pseudopods mimicking the effect of PP2A inhibition and actin polymerization defects. These aberrations were accompanied by abnormal hyperphosphorylation of multiple components of the actin cytoskeleton and were rescued both in vitro and in vivo by inhibiting upstream kinases such as PKA, PKC, or AMPK. These data reveal an unexpected role of Mastl in actin cytoskeletal dynamics in postmitotic cells and suggest that the thrombocytopenia-associated mutation in MASTL is a pathogenic dominant mutation that mimics decreased PP2A activity resulting in altered phosphorylation of cytoskeletal regulatory pathways.
\end{abstract}

\section{Introduction}

MASTL (microtubule-associated serine/threonine protein kinaselike, also known as Greatwall) is a recently characterized kinase with critical functions in the maintenance of mitosis $(1,2)$. This kinase was originally discovered in Drosophila screenings for cell-cycle mutants (3-5) and was later shown to phosphorylate endosulfine (Ensa) and Arpp19, two small proteins that when phosphorylated function as PP2A-B55 inhibitors $(6,7)$. Depletion of Greatwall in flies and Xenopus leads to defective chromosome condensation and segregation, as a consequence of the hyperactivation of PP2A-B55 complexes, and the subsequent dephosphorylation of cyclin-dependent kinase 1 (Cdk1) substrates $(4,8)$. Less is known about the physiological relevance of the mammalian MASTL ortholog, although knockdown and knockout assays suggest that it also participates in chromosome condensation and maintenance of the mitotic state in a PP2A-B55-dependent manner (9-13).

Before the functional role of MASTL was studied in mammalian cells, a missense mutation in the human MASTL locus (located in chromosome 10p11-12) was found to perfectly segregate

Authorship note: BH and MT contributed equally to this work. Conflict of interest: The authors have declared that no conflict of interest exists. License: Copyright 2018, American Society for Clinical Investigation.

Submitted: April 27, 2018; Accepted: September 18, 2018.

Reference information: / Clin Invest. 2018;128(12):5351-5367.

https://doi.org/10.1172/JCl121876. with nonsyndromic autosomal dominant thrombocytopenia, also known as thrombocytopenia-2 (THC2) (14). These patients were characterized by incomplete differentiation of megakaryocytes and moderate thrombocytopenia, with a certain propensity toward easy bruising and minor bleeding $(15,16)$. The mutation, a substitution of cytosine for guanidine ( $\mathrm{G}$ to $\mathrm{C}$ ) at nucleotide position 565 , was present in all thrombocytopenic family members, causing a predicted substitution of aspartic acid for glutamic acid (E167D) in the human MASTL gene (14). In addition to the E167D substitution in MASTL, additional mutations in 2 genes in the THC2 region of chromosome 10p11-12 have been linked to congenital thrombocytopenia. These include specific mutations in ACBD5 and the 5 '-UTR of $A N K R D 26$, the ankyrin repeat domain 26 gene (17). ANKRD26 mutations are the most frequent finding in patients with THC2 (18), and the 3 affected genes are very close in human chromosome 10p12.1 (ACBD5-MASTL-YME1L1-ANKRD26, centromeric to telomeric), raising questions about the relative contribution of MASTL mutations to thrombocytopenia $(17,19)$.

In order to gain new insights into the biological significance of Mastl in mammalian tissues, we generated mutant mice with specific ablation of the Mastl gene in mature megakaryocytes as well as a new knockin model carrying the thrombocytopenia-associated mutation (E166D in the mouse). This mutation in Mastl does not result in reduced activity as originally thought (14), but rather is accompanied by increased phosphorylation of Cdk and PP2A substrates, suggesting a gain-of-function alteration that results in 
A



D



E

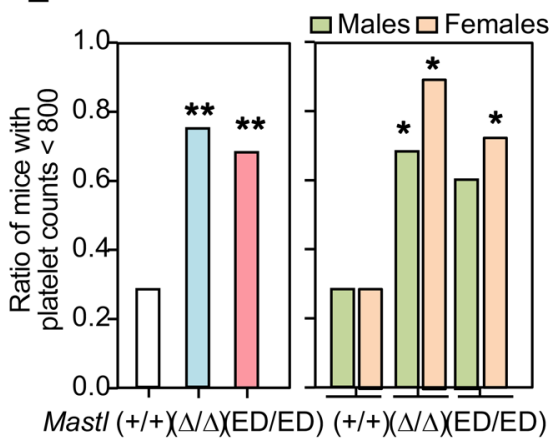

B

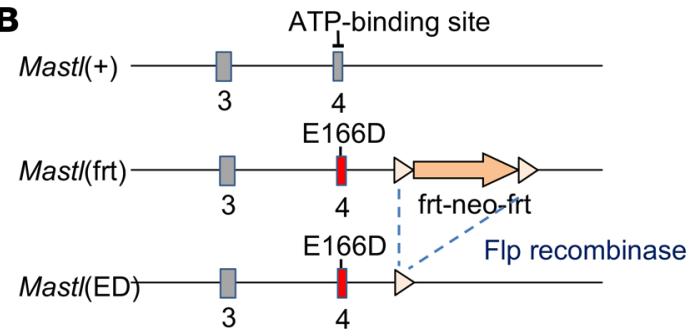

G
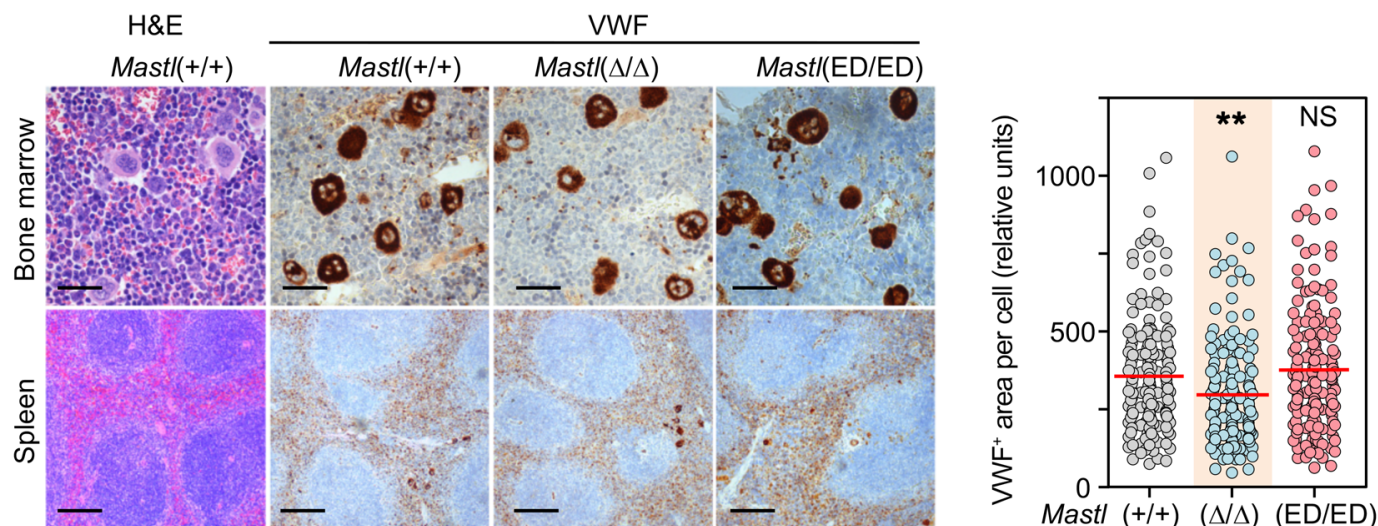

H


Figure 1. Mild thrombocytopenia in Mast/( $\Delta / \Delta)$ and Mast/(ED/ED) mice. (A) Representation of the Mast/(lox) and Mast/( $\Delta$ ) alleles used in this study. A Pf4-Cre transgene was used to generate megakaryocyte-specific Mast/-null mice. (B) Generation of the Mast/(E166D) [Mast/(ED)] allele. The frt-neo_resistance-frt cassette was removed after crossing with Flp-expressing mice. In $\mathbf{A}$ and $\mathbf{B}$, White and orange triangles represent lox or frt sequences, respectively. (C) Expression of Mastl in $\mathrm{CD}_{4} 1^{+}$bone marrow cells from mice of the indicated Mast/ genotypes. Lysates from NIH3T3 cells were used as a control. Representative image from 2 independent experiments. See complete unedited blots in the supplemental material. (D) Platelet levels in 12-week-old male (blue) or female (pink) mice with the indicated genotypes. Blue line indicates a concentration of $800 \times 10^{6}$ platelets $/ \mathrm{ml}$ as a reference. (E) Percentage of mice with fewer than $800 \times 10^{6} \mathrm{platelets} / \mathrm{ml}$ (using mice from panel D). Male and female mice are represented by separate bars (right). (F) Levels of TPO in peripheral blood from the indicated mice. Cdc20-deficient mice, which display severe thrombocytopenia (33), were used as a control ( $n \geq 4$ mice per genotype). (C) Representative micrographs of bone marrow from mice of the indicated genotypes. Images represent more than 3 mice per genotype analyzed. Scale bars: $50 \mu \mathrm{m}$. Plot shows quantification of the VWF signal in more than 100 megakaryocytes per genotype. Data are shown as the mean. (H) Quantification of CD41+ and CD42+ cells in bone marrow cells from mice of the indicated genotypes. (I) Quantification of the ploidy in $C D 41^{+} C D 42^{+}$double-positive bone marrow cells from mice of the indicated genotypes. No significant differences were observed among the different genotypes ( $n=3$ per genotype; data are shown as the mean). ${ }^{*} P<0.05,{ }^{* *} P<0.01$, and ${ }^{* * *} P<0.001$; Student's $t$ test with Welch's correction (D, F, G, and I) and 1-way ANOVA (E). 
decreased PP2A activity. Whereas genetic ablation of Mastl results in deficient maturation of megakaryocytes in vivo, Mastl E166Dmutant mice display defective dynamics in the actin cytoskeleton during platelet activation, accompanied by an altered pattern of protein phosphorylation. These defects can be mimicked by PP2A inhibition and partially rescued by downregulating critical kinases involving outside-in signaling. These results suggest a specific contribution of Mastl mutations in human thrombocytopenia and unveil an unexpected function for Mastl in sustaining the actin cytoskeleton in nondividing cells, a function that may have significant implications in human disease.

\section{Results}

Mastl deficiency, but not the E166D mutation, results in defective maturation in megakaryocytes. We first made use of a conditional allele [Mastl(lox)] generated in our laboratory (12), in which exon 4, carrying essential domains for kinase activity, can be deleted upon activation of Cre recombinase, resulting in a Mastl-null allele (Figure 1A). Since homozygous germline ablation of Mastl [Mastl(-/-)] results in early embryonic lethality (12), we decided to specifically ablate Mastl in mature megakaryocytes and platelets by using Pf4Cre-transgenic animals (20), thus generating Pf4-Cre $\operatorname{Mastl}(\Delta / \Delta)$ mice [hereafter referred to as $\operatorname{Mastl}(\Delta / \Delta)$ mice]. To mimic the alteration found in thrombocytopenia, we also generated a knockin allele carrying the ortholog mutation found in human patients [corresponding to E166D in the mouse; $\operatorname{Mastl(ED)}$ allele; Figure 1B]. Whereas deletion of exon 4 in knockout $\operatorname{Mastl}(\Delta / \Delta)$ mice results in a frameshift preventing the generation of transcripts or protein, Mastl(ED/ED)-knockin mice express normal levels of mutant mRNA (Supplemental Figure 1A; supplemental material available online with this article; https://doi.org/10.1172/JCI121876DS1) or protein (Figure 1C) in platelets or megakaryocytes.

$\operatorname{Mastl}(\Delta / \Delta)$ and Mastl(ED/ED) mice were viable and fertile and showed no overt abnormalities. The development of the hematopoietic system and its progenitors was normal in these models (Supplemental Figure 1B). However, both mutant mice displayed reduced platelet counts in peripheral blood $[20 \%$ reduction in $\operatorname{Mastl}(\Delta / \Delta)$ and $\sim 15 \%$ reduction in $\operatorname{Mastl}(\mathrm{ED} / \mathrm{ED})$ mice], and a significant percentage of 8 - to 12 -week-old animals had reduced $\left(<700 \times 10^{3}\right.$ platelets/ $\mu$ l blood) platelet counts (Figure 1, D and E). While thrombocytopenia was more obvious in $\operatorname{Mastl}(\Delta / \Delta)$ mice, the trend observed in young $M a s t l(E D / E D)$ was conserved in older (50-week-old) mice as well as in heterozygous Mastl(+/ED)-mutant mice (Supplemental Figure 1, C and D). Finally, although the mean volume of platelets was not affected in these mutants (Supplemental Figure 1E), the levels of TPO were slightly elevated in $\operatorname{Mastl}(\Delta / \Delta)$ and $\operatorname{Mastl}(\mathrm{ED} / \mathrm{ED})$ mice (Figure $1 \mathrm{~F}$ ), suggesting the presence of physiological defects in platelet numbers or function.

To understand the cellular basis of these defects, we next analyzed the maturation of megakaryocytes in vivo. $\operatorname{Mastl}(\Delta / \Delta)$ megakaryocytes in the bone marrow displayed decreased expression of Von Willebrand factor (VWF), a glycoprotein increasingly produced during the maturation of these platelet-producing cells (Figure 1G). This defect, however, was not obvious in Mastl(ED/ ED) mice. $\operatorname{Mastl}(\Delta / \Delta)$ mice also displayed reduced levels of fully matured megakaryocytes (as scored by double $\mathrm{CD} 41^{+} \mathrm{CD} 42^{+}$ staining) in the bone marrow (Figure $1 \mathrm{H}$ ), although the ploidy of these cells was not affected (Figure 1I). Mastl(ED/ED) mutants, however, did not display defects in VWF expression, CD41/CD42 levels, or ploidy (Figure 1, G-I).

Altered platelet function in Mastl-null and Mastl E166D mice. Circulating platelet counts reflect the balance between platelet production and clearance. We therefore tested platelet function by subjecting Mastl-mutant mice to different assays. We first examined the circulating half-life of platelets by administering a DyLight 488-labeled anti-CD42c antibody. Both Mastl-deficient and Mastl E166D mice displayed a significant reduction in the half-life of the circulating platelets (Figure 2A), suggesting that increased clearance also contributed to the thrombocytopenia observed in Mastl-deficient mice and possibly explaining the defects in platelet counts seen in Mastl(ED/ED) mice. We did not find evidence for increased clearance of $\mathrm{VWF}^{+}$cells in liver sections (Supplemental Figure 2A) or for protein desialylation using Maackia amurensis lectin (MAL1) or Ricinus communis agglutinin 1 (RCA-1) binding assays (Supplemental Figure 2B). However, both $\operatorname{Mastl}(\Delta / \Delta)$ and Mastl(ED/ED) platelets showed increased levels of annexin V (Supplemental Figure 2C), suggesting apoptosis as a potential mechanism to explain the increased platelet clearance in these models. In agreement with the reduced platelet counts, both $\operatorname{Mastl}(\Delta / \Delta)$ and $\operatorname{Mastl}(\mathrm{ED} / \mathrm{ED})$ mice displayed increased bleeding times (Figure 2B) and defective clot retraction (Figure 2C).

We further evaluated the differences between these 2 models by inducing pulmonary embolism via i.v. injection of collagen and epinephrine. We found that lack of Mastl in the $\operatorname{Mastl}(\Delta / \Delta) \bmod -$ el resulted in a significant protection against death in this mouse model, which correlated with the reduced number of thrombi observed in the lungs (Figure 2, D and E). Surprisingly, the presence of the Mastl E166D mutation resulted in the opposite phenotype: accelerated death accompanied by abundant and large thrombi in the lungs. In an independent model in which ferric chloride $\left(\mathrm{FeCl}_{3}\right)$ was used to induce vascular injury in the context of an aseptic closed vascular system, lack of Mastl resulted in slightly increased vessel patency, whereas Mastl E166D mice displayed accelerated vessel occlusion in the presence of large thrombi (Figure 2, F and G). Although $\operatorname{Mastl}(\Delta / \Delta)$ mice had lower peripheral platelet counts than did Mastl E166D mutants, the differences found in these in vivo assays suggest a fundamental difference in the defects caused by the lack of Mastl or the presence of the thrombocytopenia-associated mutation.

Functional defects in mutant platelet activation and spreading. To investigate the basis for the differences between the 2 Mastlmutant platelets, we tested the response of these cells to several stimuli. We observed no significant differences in the aggregation of Mastl(ED/ED) platelets in response to thrombin (Figure 3, A and B) or collagen (data not shown), whereas Mastl-deficient platelets were significantly inefficient in these assays. Exposure of isolated platelets to thrombin did not result in differences in the levels of high-affinity activated integrin $\alpha \operatorname{IIb} \beta 3$ (fibrinogen receptor or CD41a), suggesting no defects in the early inside-out pathway in mutant platelets (Figure 3C). However, while binding to fibrinogen was deficient in $\operatorname{Mastl}(\Delta / \Delta)$ platelets, it was enhanced in Mastl (ED/ED)-mutant platelets, perhaps suggesting a hyperstabilization of fibrinogen-receptor complexes or deficient downstream events in the knockin model (Figure 3D). Both $\operatorname{Mastl}(\Delta / \Delta)$ and 
A

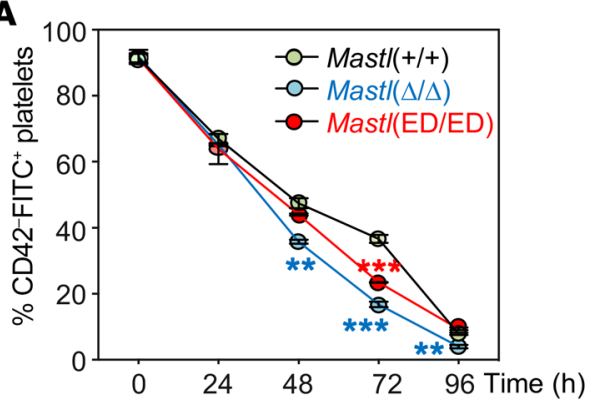

B



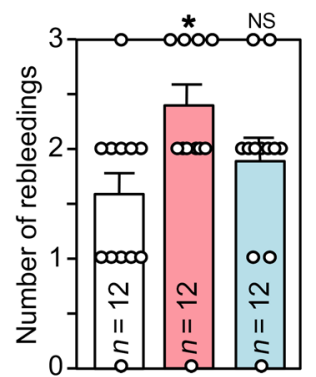

Mastl (+/+) $(\Delta / \Delta)(E D / E D)$
C

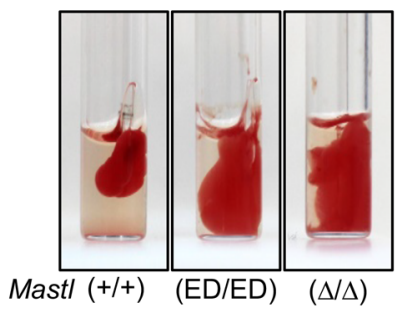

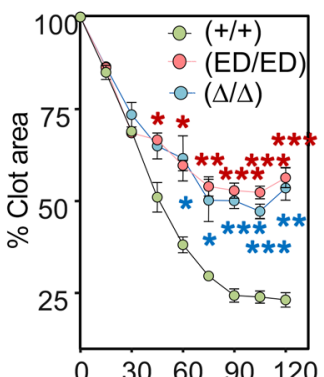

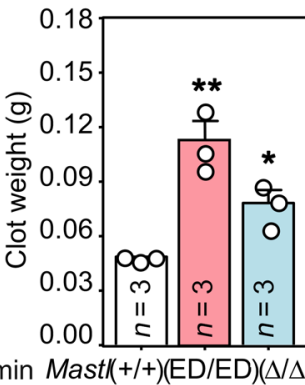

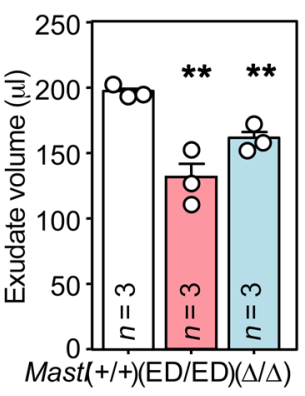

D

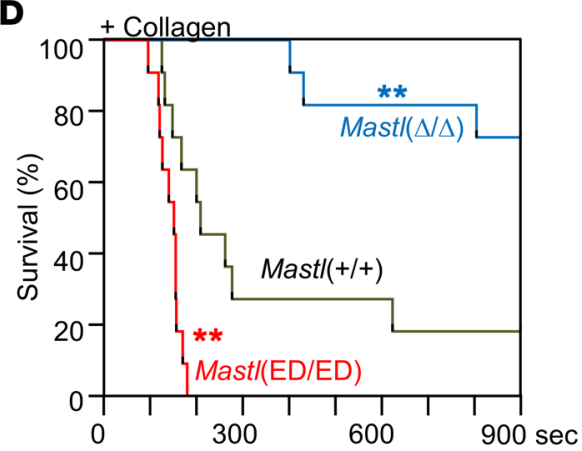

F

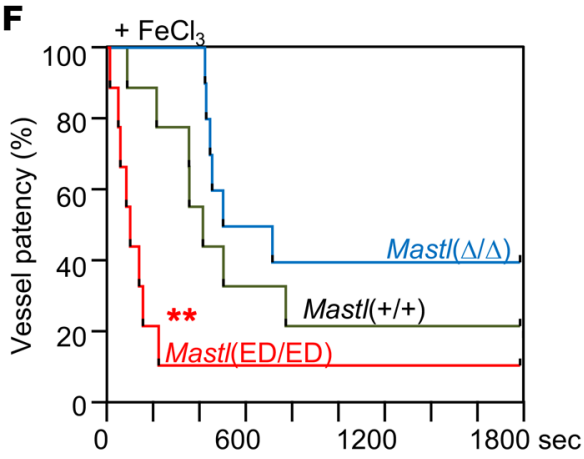

E

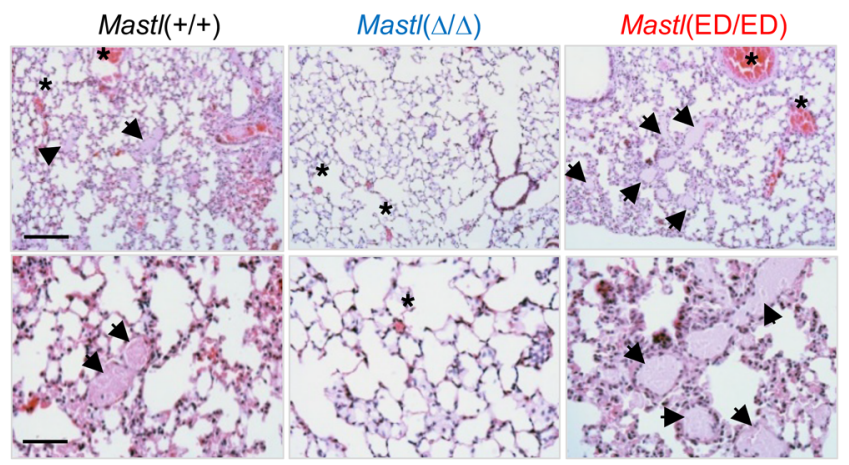

G



Figure 2. Altered platelet function in Mastl-mutant mice. (A) Platelets were labeled with DyLight 488-labeled anti-CD42c (CPIb $\beta$ ) antibody and then monitored for the percentage of DyLight $488^{+}$versus total CD41+ platelets stained with an APC-labeled anti-CD41 antibody. $n=3$ mice per genotype. (B) Bleeding time (left) and number of rebleedings (right) in mice of the indicated genotypes ( $n=12$ per genotype). (C) Clot retraction in mice of the indicated genotypes. Representative images of clots from 3 different mice per genotype are shown. Plot represents the percentage of the area of the clot versus $t 0$. Histograms on the right show the clot weight and exudate volume after 120 minutes. Data are shown as the mean $\pm \mathrm{SEM}$. $(\mathbf{A}-\mathbf{C}){ }^{*} P<$ 0.05 , ${ }^{* *} P<0.01$, and ${ }^{* * *} P<0.001$; Student's $t$ test. (D) Survival of control and mutant mice after induction of pulmonary embolism using collagen. $n=12$ mice per genotype. ${ }^{* *} P<0.01$; log-rank test with Bonferroni's correction. (E) Representative micrographs show thrombi (arrows) and noncoagulated blood (asterisks). $n=3$ mice analyzed. Scale bars: $100 \mu \mathrm{m}$. (F) $\mathrm{FeCl}_{3}$-induced carotid artery injury model. $n=9$ mice per genotype. ${ }^{* *} P<0.01$; log-rank test with Bonferroni's correction. (G) Representative Carstair-stained images of thrombi formed in the carotid artery after injury with $5 \%$ $\mathrm{FeCl}_{3}(n=3$ mice). Scale bars: $50 \mu \mathrm{m}$ (top) and $10 \mu \mathrm{m}$ (bottom). 
A

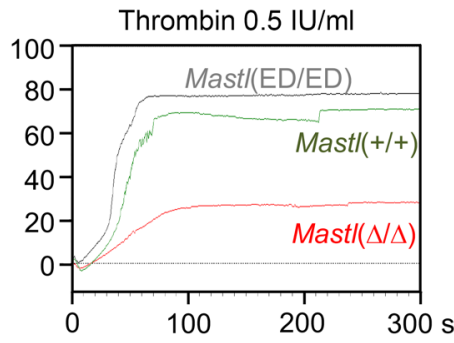

B

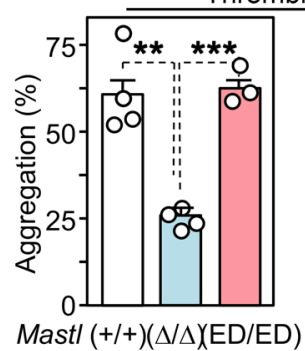

Thrombin $0.5 \mathrm{lU} / \mathrm{ml}$

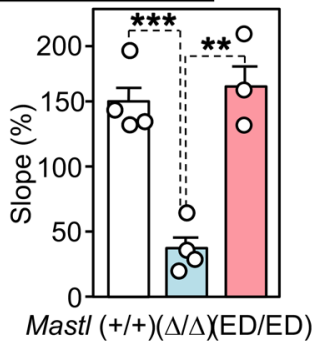

C

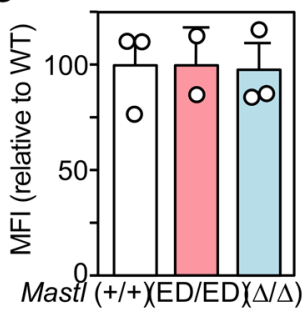

D

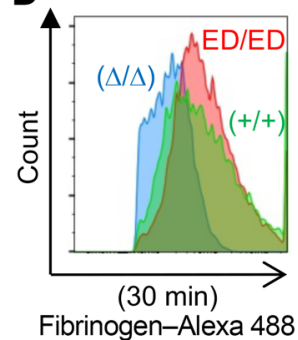

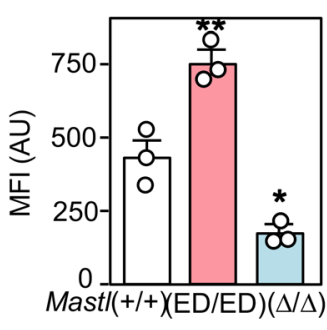

Mast $(+/+)(E D / E D)(\Delta / \Delta)$

E
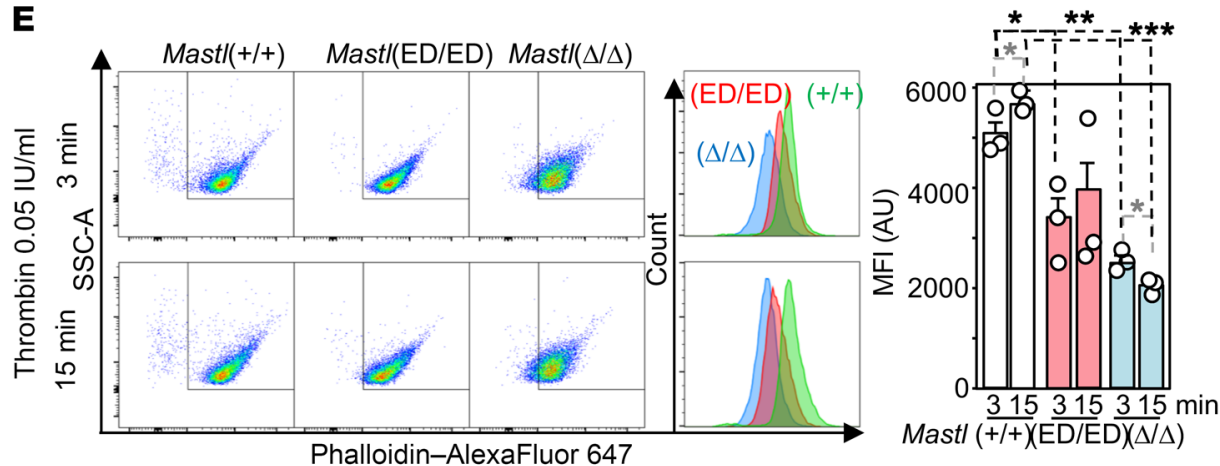

Mastl $(+/+)(\operatorname{ED} / \mathrm{ED})(\Delta / \Delta)$

$\mathbf{F}$

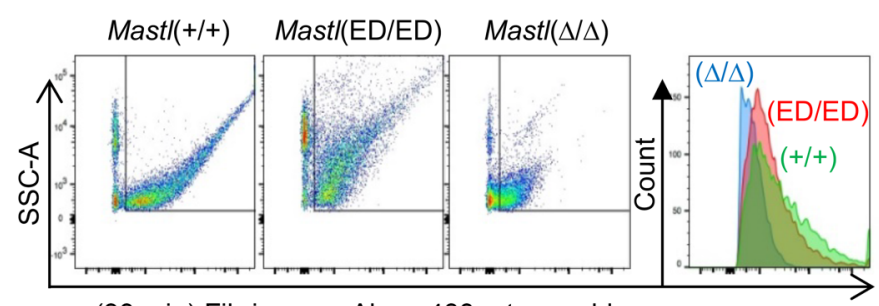

(30 min) Fibrinogen-Alexa 480 + trypan blue

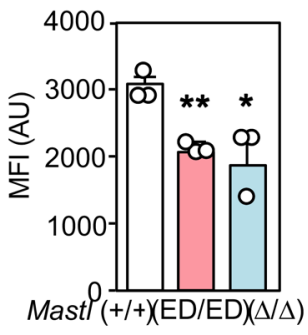

Figure 3. Platelet activation in Mast/( $\Delta / \Delta)$ and Mast/(ED/ED) mutant mice. (A) Representative light transmission aggregometry (LTA) curves of platelets from mice of the indicated genotypes in the presence of $0.5 \mathrm{IU} / \mathrm{ml}$ thrombin. (B) Percentage of aggregation and slope of the aggregation curves from LTA assays. (A and B) $n=4$ mice per genotype. (C) Flow cytometric detection of activated mouse integrin $\alpha$ llb $\beta 3$ (CD41a) using the specific conformational antibody JON/A ( $n$ = 3 mice per genotype). (D) Soluble fibrinogen binding quantification by flow cytometry in washed platelets activated with $0.05 \mathrm{IU} / \mathrm{ml}$ thrombin for 30 minutes ( $n=3$ mice per genotype). (E) Quantification of F-actin content by flow cytometry in activated platelets with thrombin for 3 and 15 minutes, as indicated $(n=3$ mice per genotype). (F) Quantification of platelet fibrinogen uptake by flow cytometry of thrombin-activated platelets in the presence of Alexa Fluor 488-labeled fibrinogen ( $n=4$ mice per genotype). SSC-A, side scatter area. Data in $\mathbf{B}-\mathbf{F}$ are shown as the mean \pm SEM. ${ }^{*} P<0.05$, ${ }^{* *} P$ $<0.01$, and ${ }^{* *} P<0.001$; Student's $t$ test.
$\operatorname{Mastl(ED/ED)~platelets~showed~a~defect~in~the~generation~of~actin~}$ fibers after stimulation with fibrinogen when compared with control platelets, indicating defects in cytoskeletal dynamics in both models (Figure 3E). Fibrinogen uptake, a process that depends on endocytosis as well as reorganization of the actin cytoskeleton, was also deficient in $\operatorname{Mastl}(\Delta / \Delta)$ and $\operatorname{Mastl}(\mathrm{ED} / \mathrm{ED})$ platelets, in line with the possible defects in outside-in signaling and/or cytoskeletal dynamics in these mutant cells (Figure 3F). Altogether, these data suggested cytoskeletal alterations in Mastl-mutant platelets, accompanied by deficient or enhanced signaling in Mastl $(\Delta / \Delta)$ or Mastl(ED/ED) platelets, respectively.

To functionally validate the observed defects in cytoskeletal regulators, we next monitored the morphological changes during platelet activation using electron microscopy and fluorescence-guided studies. Resting Mastl(ED/ED) platelets were indis- tinguishable from control cells in their size or granule composition (Figure 4A). However, these mutant cells formed bigger aggregates after activation with thrombin and showed a specific defect in the formation of lamellipodia, a structure typically composed of a dense and dynamic network of actin filaments (Figure 4B), in agreement with defects in actin cytoskeletal dynamics. We next used immunofluorescence to monitor cytoskeletal changes during platelet activation by thrombin on fibrinogen-coated surfaces at different time points. In resting conditions, platelets are characterized by the presence of a ring of microtubules and diffuse actin staining. After thrombin activation, these cellular components are redistributed to form tight rings of constricted microtubules and actin filaments, thus favoring first the formation of filopodia and later lamellipodia characteristic of cell spreading (Figure $4 \mathrm{C}$ ). In Mastl-deficient platelets, this process occurred with delayed kinet- 

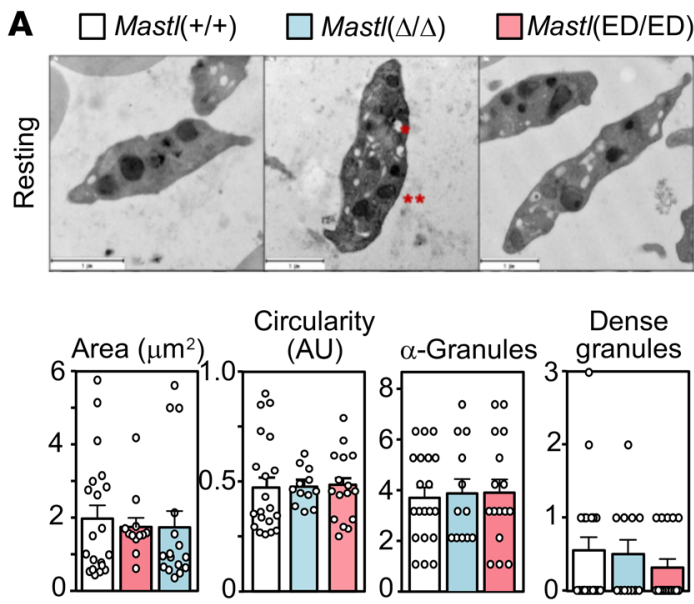

B $\square$ Mast/(+/+) $\square$ Mast/( $\Delta / \Delta) \quad \square$ Mast/(ED/ED)
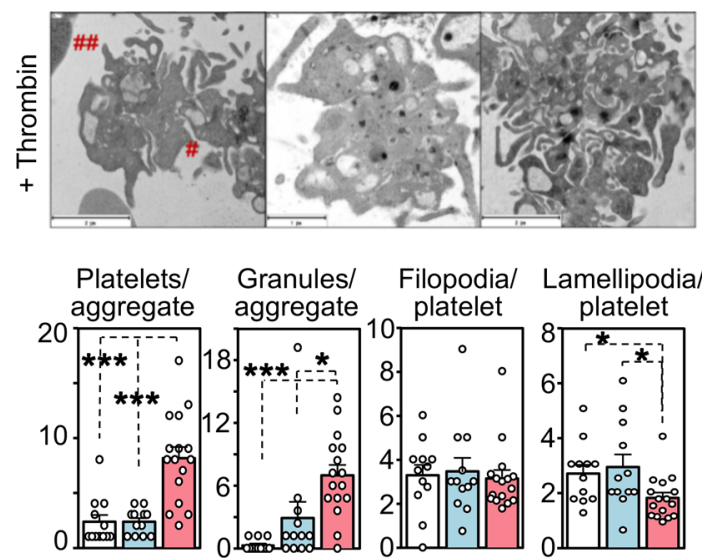

C
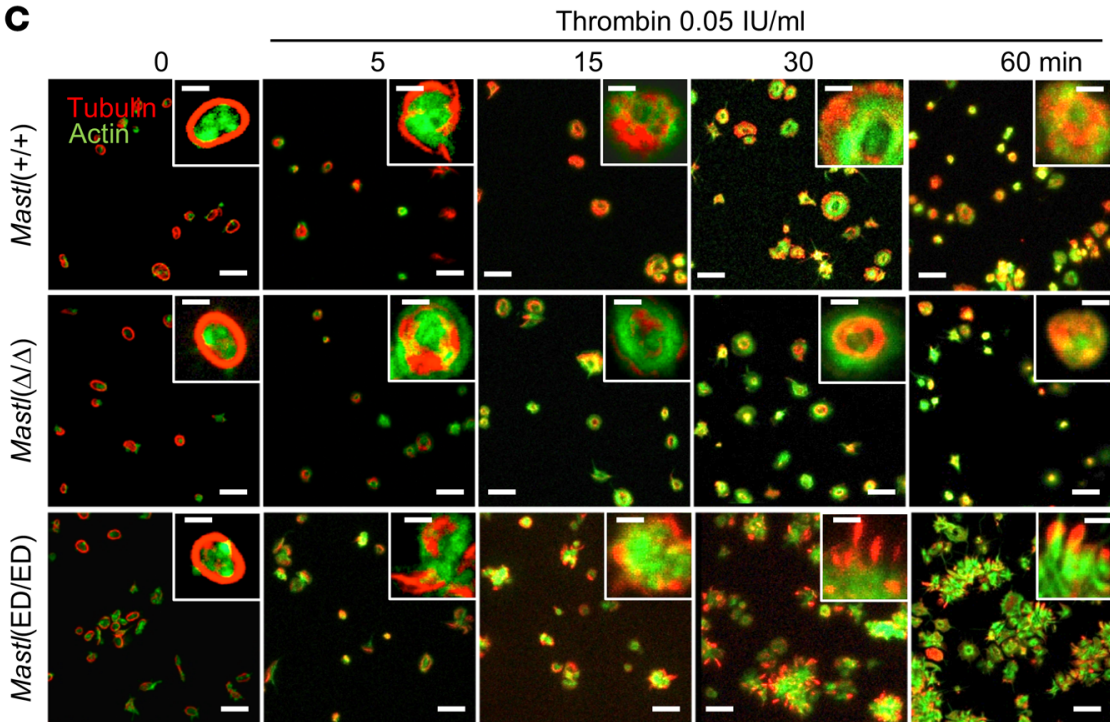

D

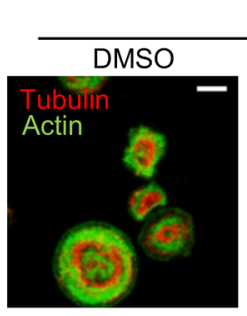

Mastl $(+/+)$
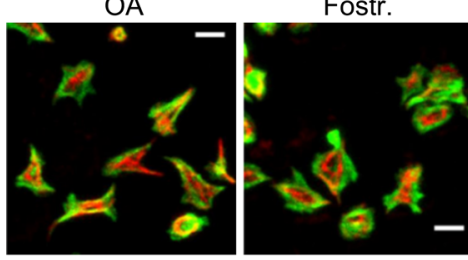

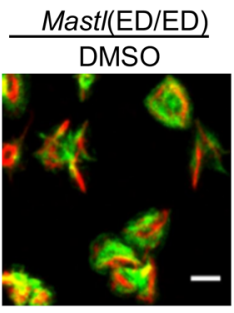

Figure 4. Platelet morphology and spreading properties in Mastl-mutant mice. Representative electron microscopic images of resting (A) and activated (B) $0.05 \mathrm{IU} / \mathrm{ml}$ thrombin for $15 \mathrm{~min}$ ) platelets from 3 mice of the indicated genotypes. Scale bars: $1 \mu \mathrm{m}$. Plots represent the mean \pm SEM of the quantification of the area, circularity ( $0-1$, with 1 being a perfect circle), and number of and $\delta$-granules per platelet. (A and $\mathbf{B}) n=3$ mice per genotype. (C) Spreading of platelets on fibrinogen. Platelets were stained with $\alpha$-tubulin (red) and phalloidin (green). Scale bars: $10 \mu \mathrm{m}$ (insets: $2 \mu \mathrm{m}$ ). Images are representative of 6 independent experiments. (D) Representative images of activated thrombin platelets spread on fibrinogen for 30 minutes, in presence of vehicle (DMSO $0.01 \%$ ) or the phosphatase inhibitors okadaic acid (OA) (250 nM) or fostriecin (Fos) $(5 \mu \mathrm{M})$. Platelets were stained as in C). Scale bars: $5 \mu \mathrm{m}$. (E) Quantification of platelet morphology after thrombin activation on fibrinogen for 30 minutes. Representative images of discoid, filopodial, and pseudopodial platelets as well as lamellipodia, abnormal lamellipodia, and spread platelets. Scale bars: $5 \mu \mathrm{m}$. Plot indicates the percentage of cells in each category ( $>150$ cells per experiment from 3 independent experiments). Data in $\mathbf{E}$ are shown as the mean \pm SEM, and statistical significance was determined by Mann-Whitney $U$ test. (A, B, and $\mathbf{E}){ }^{*} P<0.05,{ }^{*} P<0.01$, and ${ }^{*}{ }^{*} P<0.001$; Student's $t$ test with Welch's correction (A and B) and Mann-Whitney $U$ test (E).

E

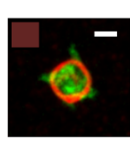

Discoid

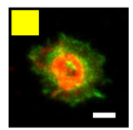

Lamellipodia



Abnormal lamellipodia
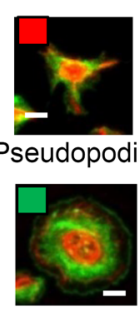

Spread
Thrombin

$0.05 \mathrm{lU} / \mathrm{m}$

(30 $\mathrm{min})$
Percentage of cells (30 min thrombin)

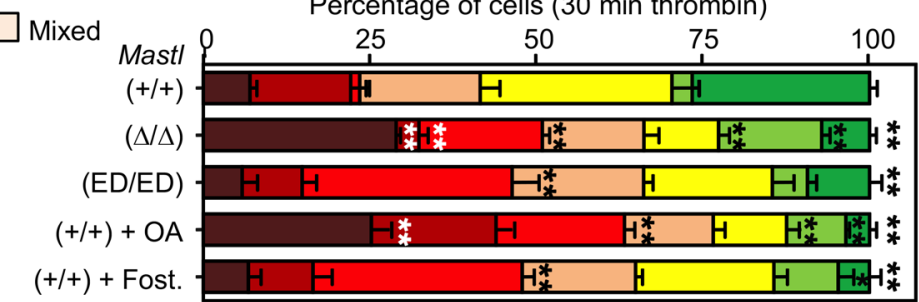


ics. The presence of Mastl E166D, however, resulted in the rapid formation of long pseudopods with abundant microtubules after activation. Actin filaments were not formed, and platelets maintained these hyperstabilized microtubule structures, ultimately leading to the formation of large aggregates at later time points (Figure 4C). As previously reported (21), this phenotype was reminiscent of that seen after the inhibition of PP2A phosphatases in WT platelets (Figure 4, D and E), suggesting that the Mastl E166D mutation may result in decreased PP2A activity.

Mastl E166D functions as a gain-of-function mutation. The MASTL E167D mutation was originally proposed to be a loss-offunction mutation (14). However, the similarities between PP2A inhibition and the Mastl E166D mutation during platelet spreading suggest that this mutation may instead confer increased inhibitory activity to Mastl over PP2A. To understand the intrinsic effect of the E166D mutation, we first performed kinase assays after transfection of exogenous cDNAs into human 293T cells. As indicated in Supplemental Figure 3A, the activity of Mastl on substrates or its autophosphorylation decreases when using a standard kinase-dead mutation in this protein (D155A mutant). However, the thrombocytopenia-associated mutant (E166D) was not defective in this assay and resulted in slightly higher levels of both phosphorylated myelin basic protein (MBP) and autophosphorylated Mastl (Supplemental Figure 3A). We also generated mouse embryonic fibroblasts (MEFs) carrying the E166D mutation in the endogenous locus [Mastl(ED/ ED)]. As shown in Supplemental Figure 3B, Mastl immunoprecipitates from Mastl(ED/ED) MEFs showed slightly increased MBP phosphorylation when compared with control samples.

Mastl is well characterized as a kinase required for maintenance of the mitotic state by inhibiting mitotic PP2A-B55 complexes, thus preventing the dephosphorylation of Cdk substrates $(8,9,11,12,22)$. We therefore evaluated the relative functionality of the endogenous Mastl E166D mutant by testing its ability to support the mitotic state in dividing MEFs. As shown in Supplemental Figure 3C, the presence of the Mastl E166D mutation resulted in increased phosphorylation of Cdk substrates (in agreement with reduced PP2A activity) after stimulation of quiescent cells with serum. These differences were not a consequence of differential progression through mitosis, as determined by the levels of cyclin B1 and phosphorylation of histone H3. We obtained similar results in cells arrested in mitosis with taxol and released after inhibition of Cdk1 to induce mitotic exit. The dephosphorylation of Cdk substrates was reduced in Mastl(ED/ED) MEFs, in agreement with reduced PP2A activity, despite similar kinetics in the exit from mitosis, as determined by the loss of cyclin B1 or histone $\mathrm{H} 3$ phosphorylation (Supplemental Figure 3D). These assays were performed in the presence of taxol to increase mitotic entry because of the difficulties in synchronizing primary MEFs, and we observed no differences in the duration of mitosis (Supplemental Figure 3E), suggesting a specific alteration in the increased phosphorylation of substrates rather than differences in mitotic cells or the duration of mitosis.

Interestingly, the pattern of phosphorylation of MAPK-Cdk substrates (characterized by proline-directed phosphosites, for which PP2A-B55 shows a certain preference) was also inverted in Mastl-null versus Mastl E166D platelets (Figure 5A), confirming the data described for MEFs. Altogether, these assays indicate that the E166D mutation does not prevent Mastl activity and, instead, may result in a gain of function, at least in the phosphorylation of putative PP2A-B55 phosphorylation substrates.

Differential phosphorylation of actin cytoskeleton proteins in Mastl E166D platelets. To gain further insights into the phosphorylation changes in mutant platelets, we performed phosphoproteomics analysis in resting and activated platelets at different time points after exposure to thrombin (Figure 5B). A total of 82,525 of 127,584 peptides identified, belonging to 1,542 phosphoproteins, were phosphorylated ( $83 \%$ enrichment). A total of 4,328 individual phosphorylation sites were precisely localized (class I) in these proteins (Figure 5B and Supplemental Table 1).

In resting Mastl(ED/ED) platelets, 65 residues (in 61 proteins) were hyperphosphorylated [ $\log _{2}$ fold change (FC) Mastl(ED/ED)/ $\operatorname{Mastl}(+/+)>0.75$ ] when compared with control platelets, with an enrichment (FDR <0.005) in Kyoto Encyclopedia of Genes and Genomes (KEGG) pathways related to membrane signaling, focal adhesion, and the cytoskeleton (Figure 5C and Supplemental Table 2). A total of 104 residues (85 proteins) were hypophosphorylated $\left[\log _{2}\right.$ FC Mastl(ED/ED) $\left./ \operatorname{Mastl}(+/+)<0.75\right]$ in these mutant platelets, with no specific KEGG pathway or Gene Ontology (GO) biological process enriched in that set of proteins. A similar comparison in $\operatorname{Mastl}(\Delta / \Delta)$ versus $\operatorname{Mastl}(+/+)$ platelets showed no enriched pathway in the hyperphosphorylated proteins, whereas focal adhesion was enriched (FDR <0.001) among the hypophosphorylated proteins (Figure 5D and Supplemental Table 3).

The bulk of phosphorylations increased 3 minutes after activation with thrombin and decreased at later time points in platelets of all 3 genotypes (Supplemental Figure 4A). The signaling pathways involved in actin cytoskeleton reorganization upon focal adhesion was further hyperphosphorylated in Mastl(ED/ED) versus Mastl $(+/+)$ platelets (121 residues in 95 proteins hyperphosphorylated; $\log _{2}$ FC ED/WT >0.75) three minutes after the exposure to thrombin (Supplemental Figure 4B), whereas no special pathway was enriched among the proteins hyperphosphorylated in $\operatorname{Mastl}(\Delta / \Delta)$ platelets (Supplemental Figure 4B and Supplemental Table 4). Analysis of the hyperphosphorylated sequences in Mastl(ED/ED) resting platelets showed a high frequency of CAMKII and PKA/ PKC motifs, with a smaller representation of Ser/Thr phosphorylation $[(\mathrm{S} / \mathrm{T})-\mathrm{P}]$ phosphorylation residues (Figure $5 \mathrm{E}$ ), a sequence preferentially dephosphorylated by PP2A-B55 complexes (23). Three minutes after activation with thrombin, (S/T)-P phosphorylation residues were substantially enriched in activated Mastl(ED/ ED) platelets compared with control cells (Figure 5E).

A combined analysis of sequences hyperphosphorylated in both resting and 3-minute-activated platelets (42 phosphorylation residues in 43 proteins; $\log _{2}$ FC ED/WT $>0.75$ ) suggested that focal adhesion and the actin cytoskeleton were the most significant pathways with hyperphosphorylated components in resting and activated Mastl E166D platelets (Supplemental Figure 5 and Supplemental Table 5). At later time points (15 and $45 \mathrm{~min}$ in the presence of thrombin), several additional pathways such as the chemokine signaling pathway, endocytosis, the MAPK signaling pathway, or inositol phosphate metabolism were also deregulated (Supplemental Tables 6 and 7).

The results obtained in functional assays (Figures 2-4) and proteomic studies (Figure 5) suggested a specific alteration of 
A

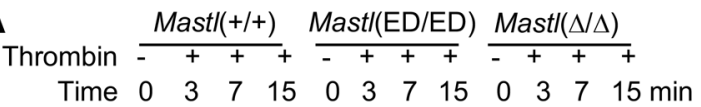

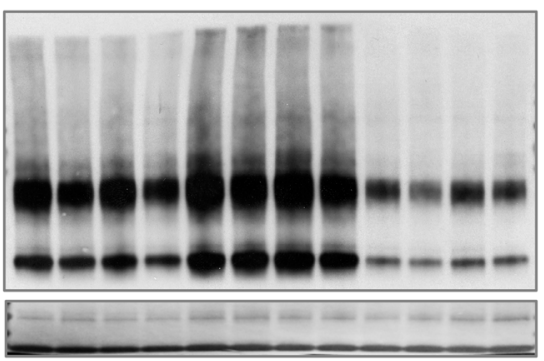
p-MAPK/CDK

(Thr) substrates

Ponceau S
B

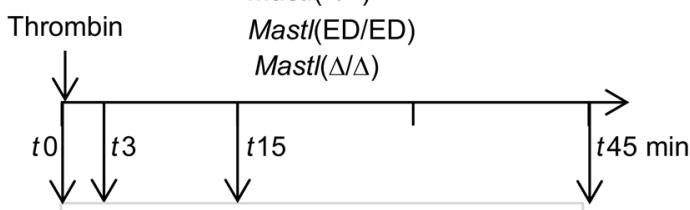

Protein extraction - Digestion - Labeling

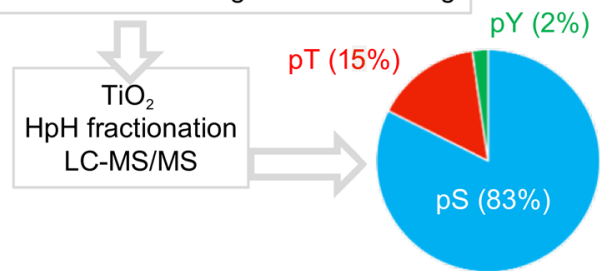

C

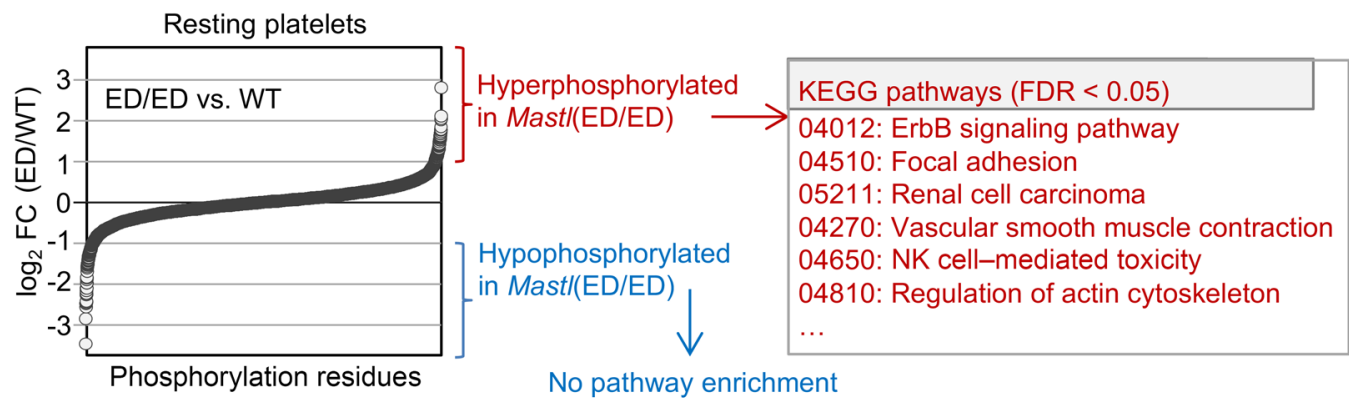

D

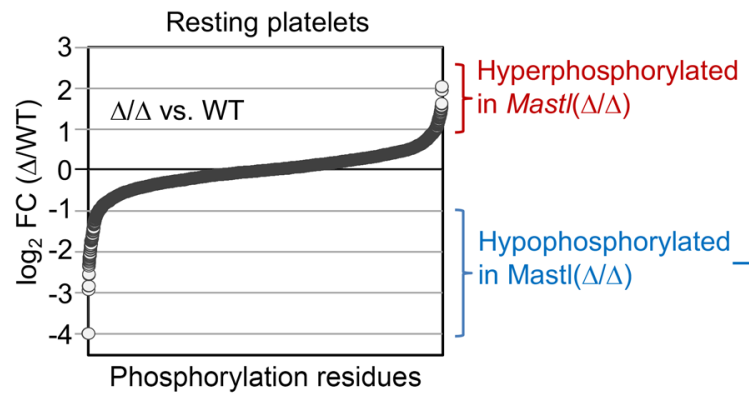

$\longrightarrow$ No pathway enrichment KEGG pathways (FDR $<0.001)$ 04510: Focal adhesion 05100: Bacterial invasion 04012: ErbB signaling pathway 05205: Proteoglycans in cancer 04611: Platelet activation

E

\begin{tabular}{|c|c|c|}
\hline Motifs & Occurrence & Kinase \\
\hline R-X-X-pS & $30.6 \%$ & CAMK2 \\
\hline $\mathrm{pS}-\mathrm{X}-\mathrm{X}-\mathrm{X}-\mathrm{X}-\mathrm{X}-\mathrm{P}$ & $16.0 \%$ & \\
\hline pS-X-X-X-P & $15.1 \%$ & \\
\hline pS-P & $15.1 \%$ & MAPK/CDK \\
\hline R-X-pS & $14.7 \%$ & $\mathrm{PKA} / \mathrm{PKC}$ \\
\hline pS-X-R & $12.5 \%$ & \\
\hline$p S-X-X-G$ & $12.5 \%$ & \\
\hline$R-X-X-X-X-p S$ & $11.2 \%$ & \\
\hline
\end{tabular}

\begin{tabular}{lrl} 
Motifs & Occurrence & Kinase \\
\hline pS-P & $25.7 \%$ & MAPK/CDK \\
R-X-X-pS & $25.1 \%$ & CAMK2 \\
pS-X-S & $20.8 \%$ & \\
pS-X-X-E & $15.8 \%$ & CK2 \\
R-X-pS & $14.9 \%$ & PKA/PKC \\
pS-X-E & $12.4 \%$ & \\
R-X-X-X-X-X-pS & $11.4 \%$ & \\
R-X-X-X-X-pS & $10.9 \%$ & \\
\hline
\end{tabular}

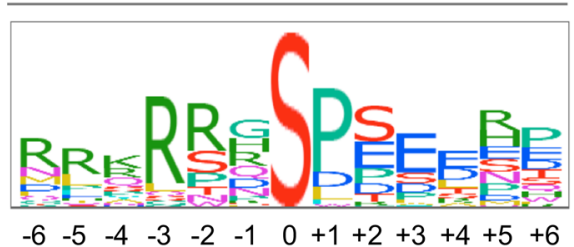

Figure 5. Phosphoproteomic analysis in Mastl-mutant platelets. (A) Levels of p-MAPK/CDK substrates (proline-directed phosphosites) in resting platelets $(0 \mathrm{~min}$ ) or platelets activated with $0.05 \mathrm{IU} / \mathrm{ml}$ thrombin for 3,7 , and 15 minutes. A representative image from 2 separate experiments is shown. See complete unedited blots in the supplemental material. (B) Schematic representation of the protocol used in the phophoproteomics experiments. Pie chart represents the percentage of peptides phosphorylated in serine (pS), threonine ( $\mathrm{pT}$ ), or tyrosine (pY) over the total number of phosphopeptides detected. A pool of platelets from 3 mice per genotype was used for each time point. (C and $\mathbf{D})$ FC ( $\left.\log _{2}\right)$ of all identified phosphosites in Mast/(ED/ED) (C) or Mast/( $\Delta / \Delta)$ (D) versus Mast/(+/+) platelets in resting conditions. Enrichment of specific Kyoto Encyclopedia of Genes and Genomes (KEGG) pathways in hyperphosphorylated $\left(\log _{2} F C \geq 0.75\right)$ or hypophosphorylated $\left(\log _{2} F C \leq-0.75\right)$ sites was calculated using the mouse platelet proteome as a background. See Supplemental Tables 2 and 3 for a complete list of the enriched pathways. (E) Analysis of hyperphosphorylated motifs in Mast/(ED/ED) versus Mast/(+/+) resting platelets (left) or 3 minutes after activation with thrombin (right) using the de novo motif finder tool from the Posttranslational Modification Database (PHOSIDA). 


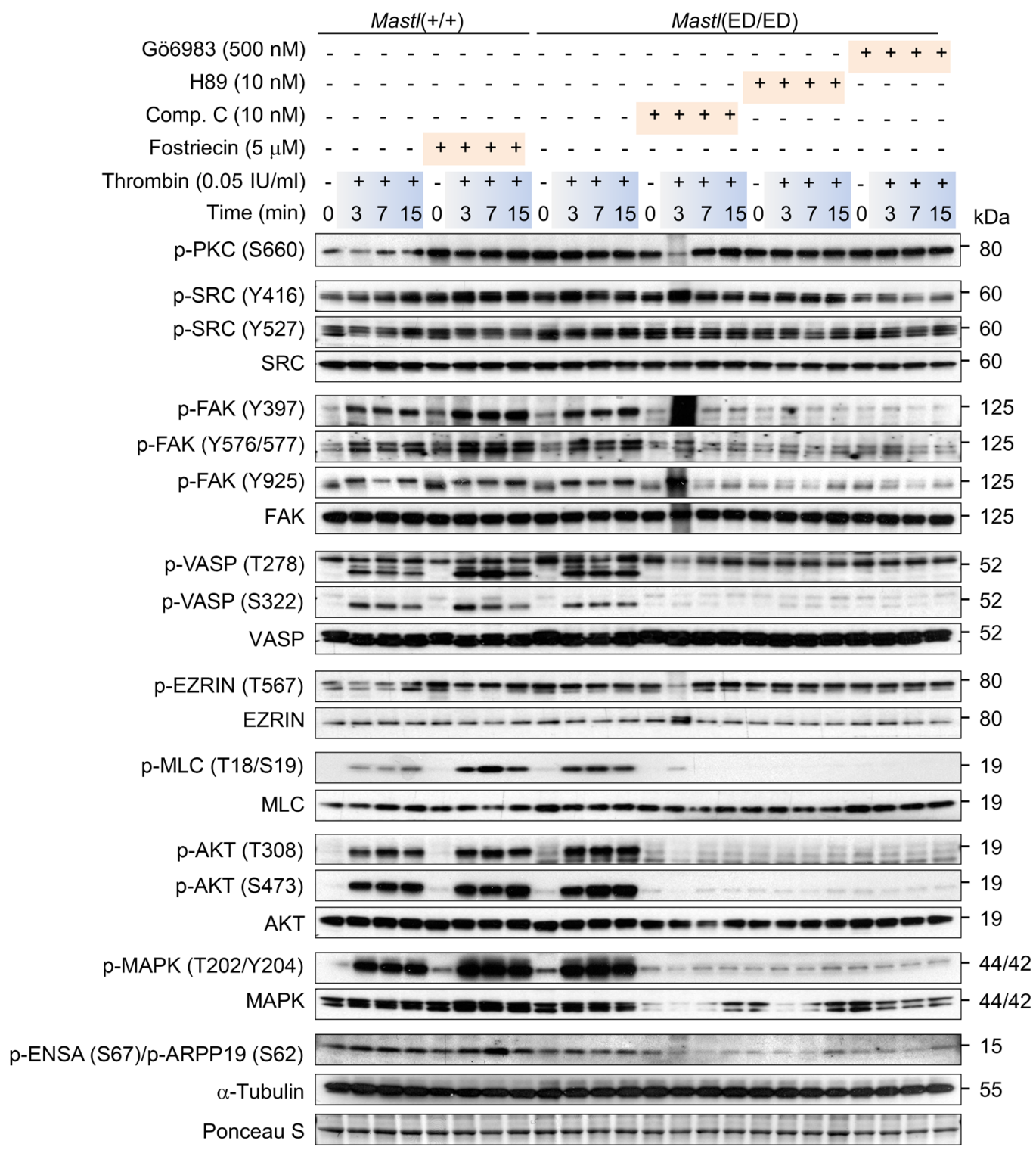

Figure 6. Activation of focal adhesion and actin dynamics pathways in Mastl-mutant platelets. Immunoblot analysis of total protein extracts from platelets in resting ( $0 \mathrm{~min}$ ) or thrombin-activated conditions ( 3,7 , and $15 \mathrm{~min})$. When indicated, platelets were pretreated with phosphatase (fostriecin) and kinase (compound C [CompC], H89, Gö6983, which inhibit Ampk, Pka, and Pkc, respectively) inhibitors for 15 minutes at $37^{\circ} \mathrm{C}$ before activation. Pools of platelets from 3 mice per genotype were used in each condition. Image is representative of 3 separate experiments. Antibodies are referred to by their commercial name, and the phosphorylation residues indicated correspond to the human nomenclature. See complete unedited blots in the supplemental material.

phosphorylated proteins, including those with proline-directed phosphosites, involved in outside-in signaling downstream of integrin $\alpha \operatorname{IIb} \beta 3$ and in actin reorganization. The catalytic subunit of PP2A is known to associate constitutively with the integrin $\alpha \operatorname{IIb} \beta 3$, preventing spontaneous outside-in signaling (24). Binding of fibrinogen to $\alpha \mathrm{IIb} \beta 3$ leads to decreased integrin-associated PP2A activity, thereby favoring the phosphorylation of downstream targets such as the enabled vasodilator-stimulated phosphoprotein (Vasp), a critical regulator whose dephosphorylation is required for the dismantling of filopodia in order to form the lamellipodia required for spreading $(25,26)$. In $M a s t l(E D / E D)$ platelets, these changes were accompanied by enhanced activation of critical regulatory kinases such as protein kinase C (Pkc), Src, or Fak (Fig- ure 6 and Supplemental Figure 6A). Activation of these pathways likely resulted in increased phosphorylation of Vasp at both Ser157 and Ser322, which are known to increase stress fiber and filopodia formation (27), as well as the regulatory light chain of myosin II (Mlc2), a reporter of active reorganization of the actomyosin cytoskeleton. Inhibition of Pkc $\delta$, Pka, or Ampk, 3 upstream kinases activated by $\alpha \operatorname{IIb} \beta 3$ during outside-in signaling and involved in Vasp phosphorylation $(25,28,29)$, prevented Vasp hyperphosphorylation and downstream events in Mastl(ED/ED) platelets (Figure 6). In addition, treatment of WT platelets with the PP2A inhibitors fostriecin (Figure 6) or okadaic acid (Supplemental Figure 6B) resulted in hyperactivation of these signaling regulators to an extent similar to that detected in Mastl(ED/ED) platelets. 
$\mathbf{A}$
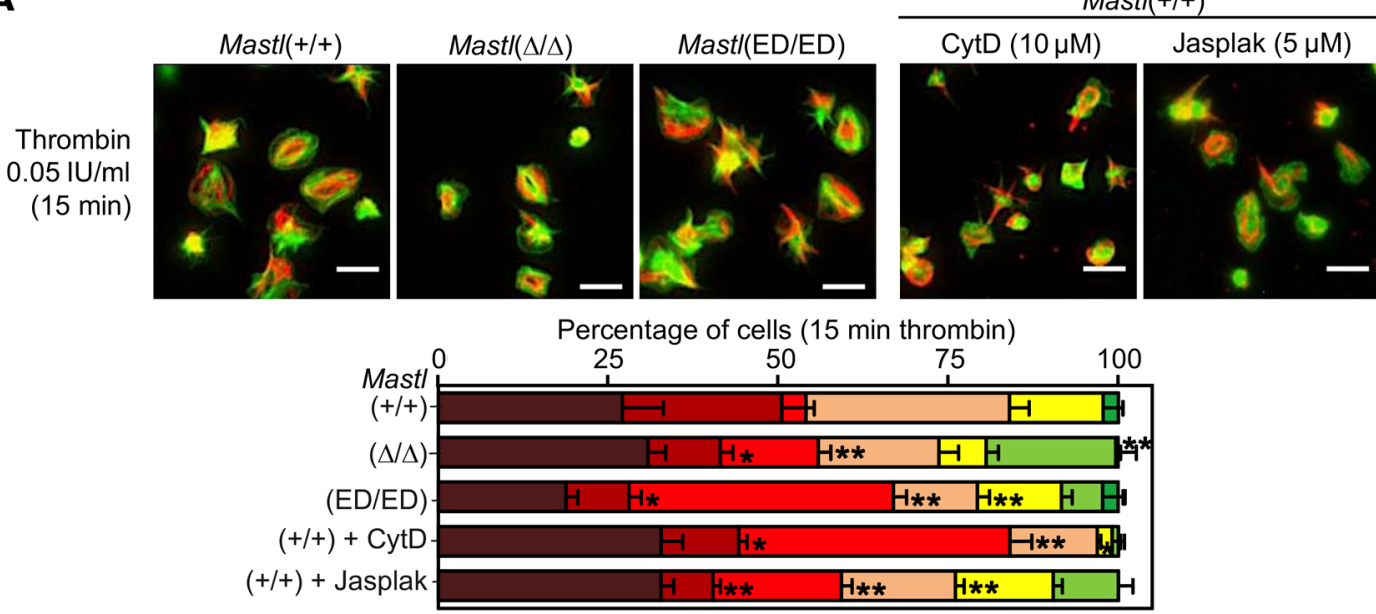

B
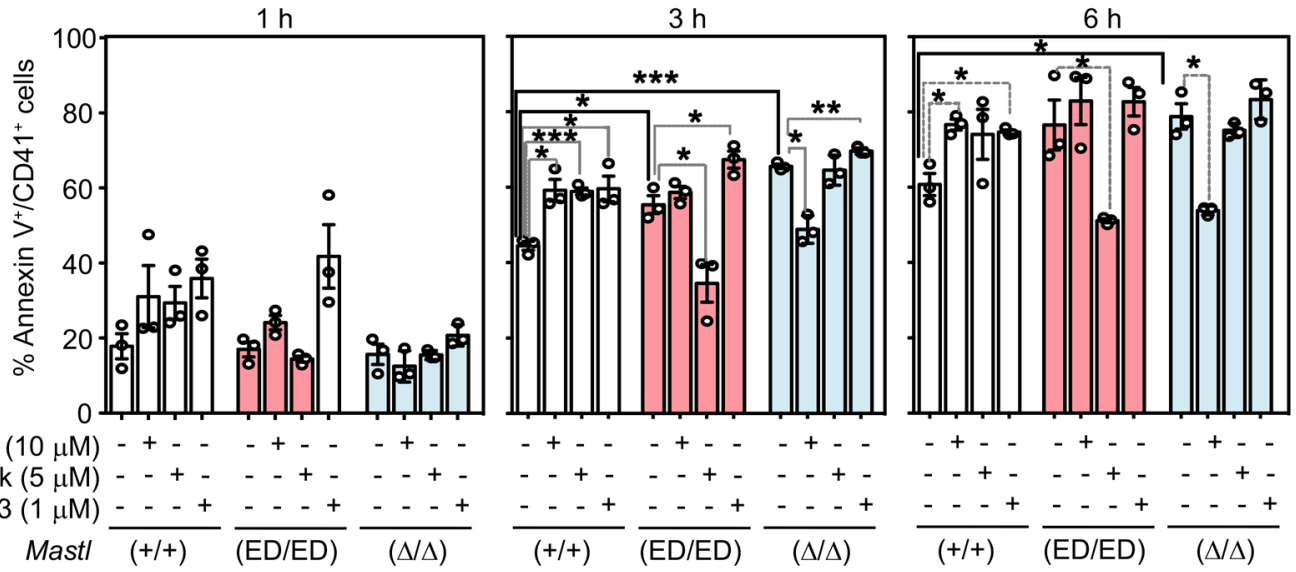

CytD $(10 \mu \mathrm{M})$ - + - - + - - + -

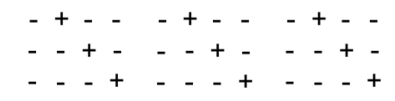

ABT-263 $(1 \mu \mathrm{M})$ - - + + - + + - + +

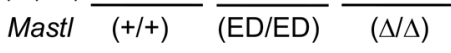

$\overline{(+/+)} \overline{(E D / E D)} \frac{--1+}{(\Delta / \Delta)}$

$(+/+)$

Mast/(ED/ED)

C
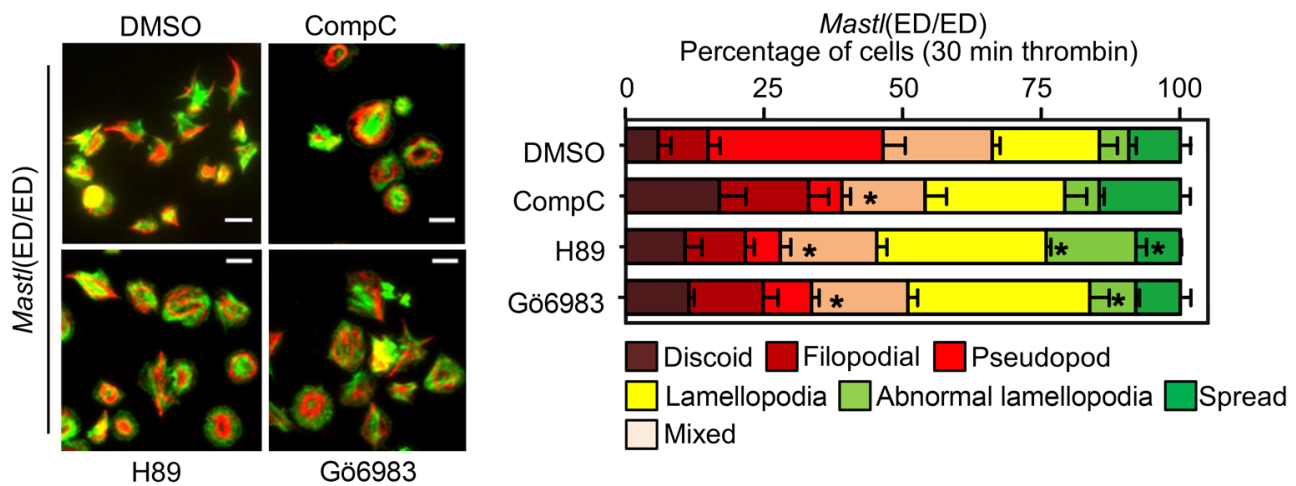

Figure 7. Platelet defects in Mast/(ED/ED)-mutant mice are mimicked with actin polymerization inhibitors and rescued by inhibiting inside-out kinases. (A) Representative images of WT platelets treated with cytochalasin D (CytD) or jasplakinolide (Jasplak) 15 minutes after activation with thrombin. Untreated WT or mutant platelets are shown as controls. (B) Percentage of annexin $\mathrm{V}^{+}$cells, as quantified by flow cytometry with specific antibodies, in platelets (as labeled with CD41-specific antibodies) from mice of the indicated genotypes in the absence or presence of cytochalasin D, jasplakinolide, or the Bcl2-family inhibitor ABT-263 (used as a control for the induction of cell death), 1, 3, or 6 hours after activation with thrombin. Data are shown as the mean \pm SEM. (C) Representative images of Mast/(ED/ED) platelets activated with $0.05 \mathrm{IU} / \mathrm{ml}$ thrombin and spread on fibrinogen for 30 minutes in the presence of vehicle (DMSO $0.01 \%$ ) or the kinase inhibitors compound C (10 nM), H89 (10 nM), or Gö6983 (500 nM). In A and C, platelets were stained with $\alpha$-tubulin (red) and phalloidin (green), and plots show the percentage (mean \pm SEM) of cells in the categories described in Figure 4E. $n>150$ cells per experiment from 3 independent experiments. Scale bars: $5 \mu \mathrm{m} .{ }^{*} P<0.05,{ }^{* *} P<0.01$, and ${ }^{* *} P<0.001$; Student's $t$ test with Welch's correction (B) and Mann-Whitney $U$ test (A and $\left.\mathbf{C}\right)$.

Functional relevance of altered actin dynamics in Mastl E166D platelets. The finding that actin regulatory networks are deregulated during the activation of $\mathrm{Mastl}(\mathrm{ED} / \mathrm{ED})$ platelets prompted us to evaluate the possible relevance of actin deregulation in the pheno- types observed in these mutant mice. Treatment of platelets with cytochalasin $\mathrm{D}$, a compound that prevents actin polymerization, resulted in a significant increase in the formation of long pseudopods with abundant microtubules, mimicking the aberrations 
A

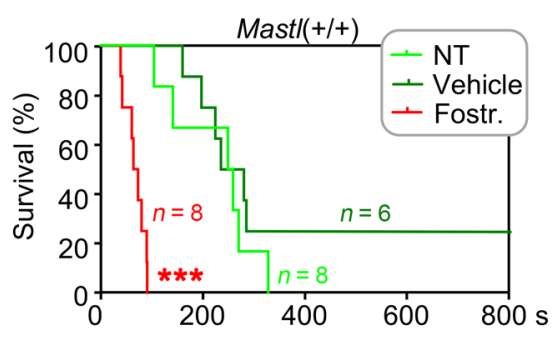

B
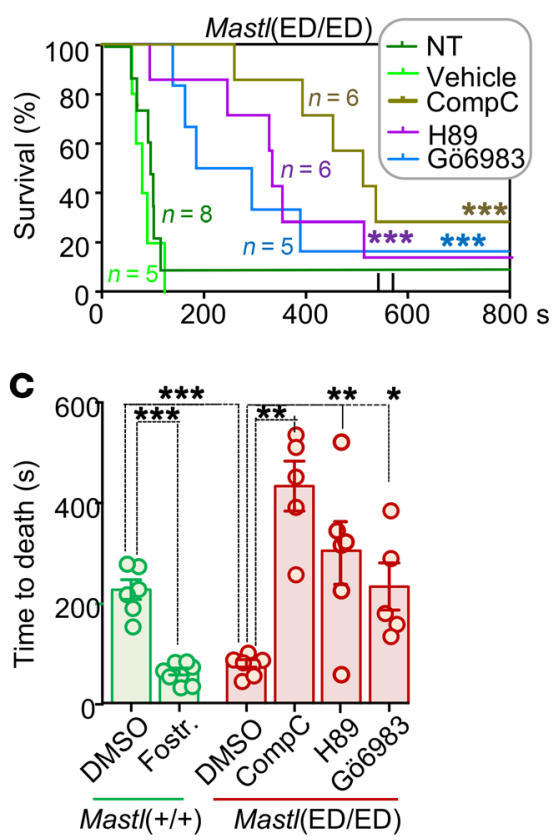

$\operatorname{Mast}(+/+)$

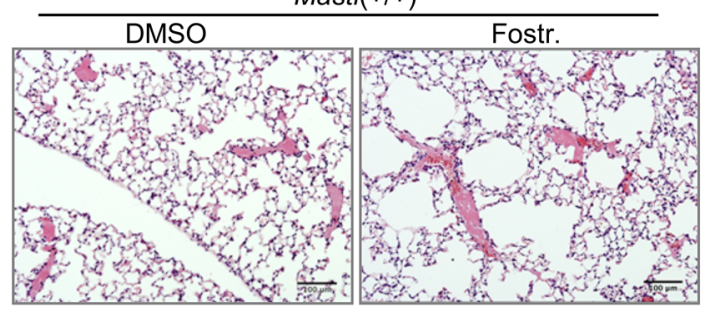

Mast/(ED/ED)
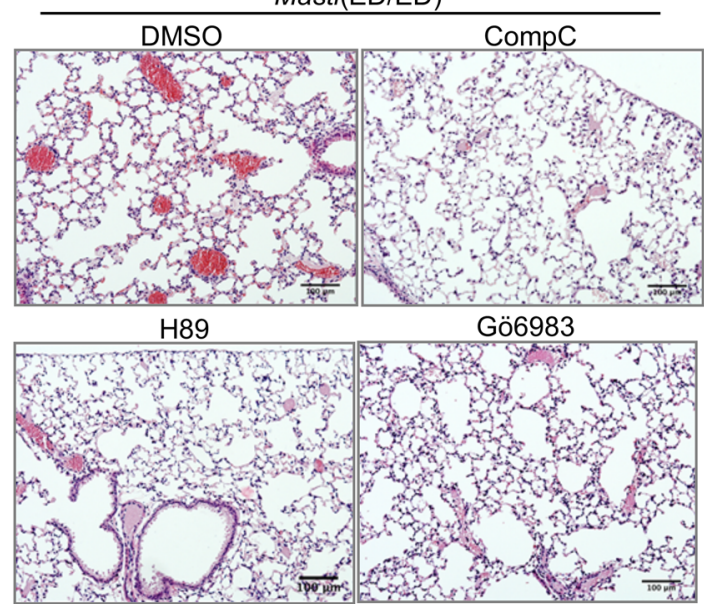

Figure 8. Functional defects in Mast/(ED/ED)-mutant platelets are mimicked with phosphatase inhibitors and rescued by inhibiting inside-out kinases in vivo. ( $A$ and B) Survival curves after pulmonary embolism in Mast/(+/+) mice treated with the phosphatase inhibitor fostriecin (Fostr.) (A), and Mast/(ED/ED) mice treated with kinase inhibitors (B) for 1 hour before the induction of pulmonary embolism. The number of mice per group is indicated in the plots. Representative images of H\&Estained lungs are shown ( $n=3$ mice per genotype). Scale bars: $100 \mu \mathrm{M}$. (C) Time to death of mice in the experimental groups in $\mathbf{A}$ and $\mathbf{B}$. Data are shown as the mean \pm SEM. ${ }^{*} P<0.05$, ${ }^{* *} P<0.01$, and ${ }^{* * *} P<0.001$; log-rank test with Bonferroni's correction (A and $\mathbf{B}$ ) and Student's $t$ test with Welch's correction (C). NT, not treated. observed in Mastl E166D-mutant platelets (Figure 7A). On the other hand, cytochalasin D resulted in increased cell death in WT platelets, but it did not enhance the increased cell death levels observed after activation of the Mastl(ED/ED) platelets (Figure 7B). Interestingly, this compound partially rescued the increased cell death observed in Mastl-null platelets. Jasplakinolide, a compound that promotes actin polymerization and prevents its disassembly, resulted in different aberrations in WT platelets that were characterized by aberrant lamellipodia (Figure 7A). Interestingly, jasplakinolide partially rescued cell death in Mastl E166D-mutant platelets but did not have a significant effect in Mastl-null platelets (Figure 7B).

We next asked whether the abnormal behavior of Mastl(ED/ ED) platelets could be rescued by inhibiting critical kinases upstream of Vasp and Mlc2 phosphorylation and actin cytoskeleton rearrangements. Indeed, treatment of Mastl(ED/ED) platelets with Ampk, Pka, or Pkc inhibitors rescued the formation of the abnormal pseudopod-like structures observed after thrombindependent activation of $M$ astl(ED/ED) platelets in a fibrinogen-coated surface (Figure 7C).

Finally, we tested the effect of these kinase and phosphatase inhibitors on blood coagulation in vivo. As shown in Figure 8A, PP2A inhibition enhanced thromboembolism formation in WT mice, thereby mimicking the effect of the Mastl E166D mutation (compare with Figure 2D). On the other hand, treatment of Mastl
(ED/ED) mice with Ampk, Pka, or Pkc inhibitors delayed embolism formation (Figure 8B) as well as embolism-induced death (Figure $8 \mathrm{C}$ ) in the presence of the thrombocytopenia-associated mutation. Altogether, these data suggest that Mastl E166D-mutant platelets display an aberrant phosphorylation pattern that may contribute to defective platelet function and thrombocytopenia.

\section{Discussion}

The Ser/Thr kinase Mastl has emerged as an essential module in the inhibition of cell-cycle phosphatases, thus ensuring the maintenance of critical phosphorylation residues during mitosis $(1,2)$. In the absence of Mastl, PP2A-B55 activity increases, resulting in deficient phosphorylation of mitotic proteins. In yeast, Mastl homologs are involved in nutrient sensing or the regulation of transcription during quiescence or meiosis in a PP2A-dependent manner (30, 31). Whether Mastl plays any role in mammalian postmitotic cells remains to be elucidated.

The identification of a missense mutation in the human MASTL gene in patients with THC2 (MIM number 188000) $(14,16)$ suggested a putative role for this kinase either during the endomitotic process in megakaryocytes or in platelet function. The mutation in MASTL (E167D) perfectly segregated with thrombocytopeniaaffected individuals, and it was not present in unaffected family members of unrelated individuals. Subsequent studies in zebra- 
fish indicated reduced thrombocyte levels upon Mastl knockdown (32), although these studies were performed using specific morpholinos to eliminate Mastl expression, and the relevance of the thrombocytopenia-associated point mutation remained unclear. Our data using conditional mouse models or a knockin expressing the E166D (homologous to E167D in humans) mutant indicate that, whereas Mastl deficiency leads to defective maturation in high-ploidy megakaryocytes, Mastl E166D megakaryocytes show no obvious alterations in these platelet precursors. Mastl ablation does not prevent mitotic entry in mammalian cells (12), and Mastl-null megakaryocytes are able to reach normal ploidy levels, probably reflecting the fact that proper chromosome condensation or segregation is not required for endomitosis, like what has been reported in aurora B-null megakaryocytes (33).

Interestingly, Mastl(ED/ED) mice display mild thrombocytopenia characterized by normal platelet size and volume and increased levels of TPO, mimicking some of the characteristics of patients with THC2 (16). THC2 patients are also characterized by other phenotypes not reproduced in Mastl E166D mice, such as defective polyploidy and megakaryocyte differentiation (16), two phenotypes that are frequently attributed to specific nucleotide substitutions in the adjacent $A N K R D 26$ gene. In fact, THC2 is now considered to be mostly a consequence of monoallelic single nucleotide substitutions in the $5^{\prime}$-UTR of the ANKRD26 gene $(17,18)$. These mutations lead to impaired binding of the transcription factors RUNX1 and FLI1, resulting in ANKRD26 overexpression, increased MAPK signaling, and defective megakaryocyte maturation and proplatelet formation (34). Given the frequency of these ANKRD26 alterations and the fact that ANKRD26 and MASTL are neighbor genes in the THC2 locus at human chromosome 10p11-12, it was unclear to what extent MASTL E167D was a passenger mutation or whether it had any causal role in the development of this disease.

Our findings showing that Mastl E166D mice display mild thrombocytopenia and defective platelet activation not only indicate a causative role for Mastl mutations in thrombocytopenia but also indicate, for the first time to our knowledge, a cell-cycle-independent role for this kinase in mammalian tissues. During the cell cycle, Mastl specifically inhibits PP2A phosphatase complexes containing B55 (B55 $\alpha,-\beta,-\gamma,-\delta$ ) regulatory subunits to counteract Cdk-dependent phosphorylation $(8,22)$. In platelets, PP2A counteracts major kinase pathways (PKC, CMK2, CK2) (21), associates with the cytoskeletal fraction under aggregating conditions (35), and regulates outside-in signaling with a significant effect on the focal adhesion pathway (36). PP2A is a critical inhibitor of the outside-in signaling pathway downstream of $\alpha \mathrm{IIb} \beta 3$, and PP2A inhibition is known to enhance $\alpha \operatorname{IIb} \beta 3$ adhesion to fibrinogen and phosphorylation of downstream events (24). PP2A directly dephosphorylates critical signaling molecules during platelet activation, such as PKC $\zeta(37)$ or VASP $(24,38)$. Inhibition of PP2A leads to defective spreading after activation with thrombin, resulting in cells with long pseudopods with hyperestabilized microtubules (21), similar to what we observed in Mastl E166D platelets (Figure 4). Inhibition of PP2A in interphasic cells is known to induce a similar phenotype that results in short, dynamic microtubules typical of mitosis (39), suggesting a certain parallelism in the mechanism of action of PP2A in preventing hyperstabilized microtubules in both platelet and premitotic cells.
The exact mechanisms that regulate Mastl kinase activity are not well established. However, glutamine 166 is predicted to be close to the $\mathrm{C}$-terminal tail required for activation of the kinase $(40,41)$, thus suggesting that the substitution of $\mathrm{E}$ by $\mathrm{D}$ may lead to different affinities for the activating tail. The common phenotypes induced by Mastl E166D and PP2A inhibition suggest that E166D is not a loss-of-function mutation as originally suggested, given the similar mutation (E-to-D) in the tyrosine kinase Jak2 (E1046D) that has been shown to abolish kinase activity (42). Our data suggest that Mastl E166D may be a functional gain-of-function alteration based on (a) increased phosphorylation of proline-directed sequences (frequently dephosphorylated by PP2A-B55 phosphatases) in fibroblasts (Supplemental Figure 3) and platelets (Figure 5A); (b) functional assays in fibroblasts (Supplemental Figure 3); (c) activation of signaling pathways (Figure 6); and (d) the fact that PP2A mimics the effects of Mastl E166D on platelet spreading (Figure 4, D and E) and in a model of pulmonary embolism (Figure 8A). However, to what extent the defects observed in Mastl-mutant platelets are a direct consequence of differences in PP2A activity or are due to alterations in other putative Mastl substrates is unclear at the moment.

Overall, the analysis of the MASTL thrombocytopenia-associated mutation in platelets has uncovered a new function for MASTL in the regulation of actin dynamics in postmitotic cells. Given the relevance of MASTL in cancer therapy (43), whether this function also contributes to cytoskeletal dynamics in proliferating or tumor cells is an intriguing possibility that deserves further research. Our data suggest that the MASTL E167D mutation may contribute to thrombocytopenia by altering the dynamics of platelet activation as a consequence of deregulated phosphorylation events affecting the outside-in pathway and actin cytoskeletal changes. The pathogenic effect of this mutation can be prevented by inhibiting critical outside-in kinases, a finding with putative implications for patients with THC2 who carry this mutation.

\section{Methods}

Generation of mutant mice. The conditional loss-of-function model of Mastl was generated by flanking exon 4 of the murine Mastl locus with loxP sites (Figure 1A) (12). These mice were crossed with Pf4-Cretransgenic mice (20) to generate megakaryocyte-specific loss of Mastl. The new thrombocytopenia knockin model was generated by replacing the WT allele with a mutant allele carrying the E166D mutation (Figure 1B), which is an analog to the E167D mutation found in human thrombocytopenia. Recombinant embryonic stem (ES) cells harboring this allele were electroporated into developing morulas, and the resulting mice were crossed with actin-Flp-transgenic mice to generate Mastl(+/ E166D) mice. Mice were maintained on a CD1 × C57BL/6J × 129Sv/J mixed background and were housed in a pathogen-free animal facility at the CNIO following the animal care standards of the institution. The animals were observed on a daily basis, and sick mice were humanely euthanized in accordance with the Guidelines for Humane Endpoints for Animals Used in Biomedical Research (Directive 2010/63/ EU of the European Parlament and Council and the Recommendation 2007/526/CE of the European Commission).

For histological examination, samples were fixed in a solution of $4 \%$ of paraformaldehyde, embedded in paraffin, and cut into $2.5-\mu \mathrm{m}$ sections. The sections were then stained with H\&E or the Carstair's Staining Kit (Electron Microscopy Sciences, catalog 26381-Series) 
following the manufacture's protocol. For immunohistochemistry, a VWF antibody (FVIII, Dako; 1:2,000) was used. Sections were examined using a Nikon Eclipse 90i microscope using a CFI Plan Apo Lambda $4 \times / 0.2$ WB20 and a CFI Plan Apo Lambda 20×/0.75 DIC/ N2 WB1.0 and processed using ImageJ software. Further details about the antibodies used in this study are included in Supplemental Table 8.

Blood analysis. For platelet counts, blood samples were collected via the mandibular vein into EDTA-coated tubes. Blood cell counts were assessed using an automated analyzer (Abacus Junior Vet). Plasmatic TPO levels were measured with a Quantikine Mouse Thrombopoietin ELISA Kit (R\&D Systems) following the manufacturer's guidelines. Plasma samples from Cdc20-deficient mice (33), which have severe thrombocytopenia, were included as a control.

Isolation and analysis of hematopoietic cells. Cells from the bone marrow or fetal liver were isolated as previously indicated (33). The tibia and femur were isolated from 8- to 12-week-old mice, and bone marrow was flushed out through the lumen of the bone by the addition of ice-cold PBS buffer (PBS, 0.5\% BSA, 5 mM EDTA). Marrow was mechanically disrupted to achieve a single-cell suspension which was then filtered through a $40-\mu \mathrm{m}$ nylon strainer to remove bone debris and subsequently subjected to erythrocyte lysis in ACK lysis buffer (150 $\mathrm{mM}$ ammonium chloride, $1 \mathrm{mM}$ potassium bicarbonate, $0.1 \mathrm{mM}$ EDTA; 90 s on ice). The lysis was stopped by the addition of $10 \mathrm{ml}$ PBS buffer, and cells were centrifuged at $200 \mathrm{~g}$ for 10 minutes. Cells were counted and subjected either directly to surface antigen staining for flow cytometry analysis or to lineage depletion with the MACS (magnetic cell sorting) Hematopoietic Progenitor (stem) Cell Enrichment Set (Miltenyi Biotec) according to the manufacturer's protocol.

Megakaryocytes were isolated from bone marrow samples by staining with monoclonal allophycocyanin (APC) CD41 antibody (BD Biosciences), followed by incubation with Anti-APC MicroBeads (Miltenyi Biotec). The cell suspension was then loaded onto a Large Cell Separation MACS Column, and megakaryocytes were isolated by positive selection in a MACS Separator and Columns (Miltenyi Biotec). For fetal liver-derived megakaryocytes, cells were obtained from whole livers recovered from E12.5 to E13.5 mouse fetuses. Single-cell suspensions were prepared by successive passages through 19-, 22-, and 25-gauge needles. Lin ${ }^{-}$cells were grown in DMEM (Gibco, Thermo Fisher Scientific) supplemented with antibiotics and 10\% FBS and stimulated with $50 \mathrm{ng} / \mathrm{ml}$ murine thrombopoietin (TPO) (PeproTech) for at least 5 days. Ploidy of the derived megakaryocytes was analyzed on days 1,3 , and 5 of differentiation by staining with FITC anti-CD 41 and $1 \mu \mathrm{g} / \mathrm{ml}$ DAPI (MilliporeSigma) in methanol-fixed, derived megakaryocytes. Ten thousand gate events were collected per experiment in a BD FACSCanto II Cytometer. Data were analyzed using FlowJo software, version 8.8.7.

To quantify bone marrow hematopoietic stem cells, freshly isolated cells from the bone marrow were stained with phycoerythrin (PE) anti-CD34, Alexa Fluor 488 anti-IL-7Ra, peridinin chlorophyll protein cyanin 5.5 (PerCP-Cy 5.5), anti-Sca-1, APC-H7, anti-cKit, PE-cyanin 7 (PE-Cy7), anti-Fc $\gamma \mathrm{R}$, and APC-labeled lineage cell detection cocktail (all from BD Biosciences). To determine the ploidy of bone marrow megakaryocytes, methanol-fixed bone marrow cells were stained with APC anti-CD42, FITC anti-CD41, and $1 \mu \mathrm{g} / \mathrm{ml}$ DAPI. In all assays, 10,000 gate events were collected per sample in a BD FACSCanto II Cytometer (BD Biosciences). Data were analyzed using FlowJo software, version 8.8.7. Details on the antibodies used are provided in Supplemental Table 8.
Platelets were isolated as described previously (44). Briefly, mice were anesthetized with ketamine $(100 \mathrm{mg} / \mathrm{kg})$ and xylazine $(10 \mathrm{mg} /$ $\mathrm{kg}$ ), and whole blood was drawn from the inferior vena cava into a syringe containing acid citrate dextrose (1 volume of anticoagulant/9 volumes of blood). Blood was mixed with 1 volume of modified HEPES-Tyrode's buffer (140 mM NaCl, $2 \mathrm{mM} \mathrm{KCl,} 12 \mathrm{mM} \mathrm{NaHCO}_{3}$, $0.3 \mathrm{mM} \mathrm{NaH}_{2} \mathrm{PO}_{4}, 1 \mathrm{mM} \mathrm{MgCl}_{2}, 5.5 \mathrm{mM}$ glucose, $5 \mathrm{mM}$ HEPES, $2 \mathrm{mM}$ EGTA, and $0.035 \%$ BSA, pH 6.7) and was centrifuged at $150 \mathrm{~g}$ for 2 minutes to obtain platelet-rich plasma (PRP). Prostaglandin E1 (PGE1) (MilliporeSigma; $5 \mathrm{nM}$ ) was then added, and platelets were pelleted by centrifugation at $1,500 \mathrm{~g}$ for 4 minutes at $37^{\circ} \mathrm{C}$. Platelet pellets were finally suspended in modified HEPES-Tyrode's buffer without EGTA and BSA ( $\mathrm{pH}$ 7.38) but in the presence of $0.02 \mathrm{U} / \mathrm{ml}$ apyrase (grade VII) (MilliporeSigma). Platelets were counted and pooled at the density necessary for each experiment.

mRNA expression analysis. mRNA extraction from platelets was performed following the protocol described for the commercial reactive TRIzol (Invitrogen, Thermo Fisher Scientific). RNA reverse transcription was performed with the High Capacity cDNA Reverse Transcription Kit (Applied Biosystems), using 500 ng total RNA in each reaction and following the protocol described in the kit. Mastl mRNA levels were measured by real-time PCR using SYBR Green PCR Master Mix (Applied Biosystems). For amplification, the following primers were used: Mastl (placed in the targeted regions of exons 3-4) forward, 5'-AGACTACCTGCACAGACATGGA-3' and reverse, 5'-TTGGAAAGGCAAAATCTGTCAGT-3'; and Gapdh, forward, 5'-TCAACAGCAACTCCCACTCTTCCA-3' and reverse, 5'-ACCCTGTTGCTGTAGCCGTATTCA-3'. Amplification was performed in an Applied Biosystems 7900HT Fast Real-Time PCR System under the following conditions: initial activation $50^{\circ} \mathrm{C}$ for 20 seconds, initial denaturation at $95^{\circ} \mathrm{C}$ for 600 seconds, and 45 cycles of $\left(95^{\circ} \mathrm{C}\right.$ for $15 \mathrm{~s}$, $60^{\circ} \mathrm{C}$ for $40 \mathrm{~s}$, and $72^{\circ} \mathrm{C}$ for $20 \mathrm{~s}$ ) at transition rates of $4.8^{\circ} \mathrm{C} /$ second, except for annealing, which was $2^{\circ} \mathrm{C} /$ second. The program for melting curve analysis was $95^{\circ} \mathrm{C}$ for 10 seconds, $65^{\circ} \mathrm{C}$ for 30 seconds with a $2.5^{\circ} \mathrm{C} /$ second transition rate, and then ramping to $95^{\circ} \mathrm{C}$ at a transition rate of $0.1^{\circ} \mathrm{C} /$ second. Ct values were determined automatically and analyzed using SDS software, version 2.2 (Applied Biosystems). Gapdh mRNA levels were used as an internal control for normalization.

Analysis of platelet lifespan. To analyze platelet lifespans, mice were injected i.v. with $0.2 \mathrm{mg} / \mathrm{kg}$ DyLight 488 -labeled anti-CD42c (GPIb $\beta$ ) antibody (Emfret Analytics). After 1 hour, $10 \mu$ whole blood from the maxillary vein was collected into EDTA-coated tubes. Whole blood was diluted (1:25) in PBS, and the PRP was obtained by centrifugation at $1,500 \mathrm{~g}$ for 5 minutes. The PRP was then stained with APC anti-CD41 (eBiosciences) and, after further dilution with PBS (1:2), the samples were analyzed. Ten thousand $\mathrm{CD} 41^{+}$gate events were collected per sample in a BD FACSCanto II Cytometer (BD Biosciences). Data were analyzed using FlowJo software, version 8.8.7, and results are expressed as a percentage of DyLight ${ }^{+}$events with respect to the total number of $\mathrm{CD} 41^{+}$events. Platelet counts were obtained daily for 5 days at the same time each day.

Tail bleeding time and clot retraction. Tail bleeding time measurements were performed as described before (45), with some modifications. Mice were anesthetized with an i.p. injection of ketamine $(100 \mathrm{mg} / \mathrm{kg})$ and xylazine $(20 \mathrm{mg} / \mathrm{kg})$. The tip of the tail was cut and immediately immersed in PBS, $\mathrm{pH} 7.4$, prewarmed at $37^{\circ} \mathrm{C}$. The mice and the prewarmed tubes of PBS were placed into an incubator at $37^{\circ} \mathrm{C}$ 
to maintain them at the same temperature during the measurements. Bleeding time was defined as the amount of time needed for the cessation of a visible blood stream for a 2-minute period. Monitoring of the bleeding times was stopped at 10 minutes by cauterizing the tails to prevent excessive loss of blood.

Clot retraction assays were performed as previously described (46). Washed platelets were counted and adjusted to $5 \times 10^{8}$ platelets/ $\mathrm{ml}$ with HEPES Tyrode's buffer supplemented with $2 \mathrm{mM} \mathrm{MgCl}_{2}, 2 \mathrm{mM}$ $\mathrm{CaCl}_{2}$, and $2 \mathrm{mg} / \mathrm{ml}$ fibrinogen (MilliporeSigma). Clot retraction assays were performed at $37^{\circ} \mathrm{C}$, without stirring, in siliconized glass cuvettes with $400-\mu$ platelet suspension in the presence of $10 \mathrm{IU} / \mathrm{ml}$ thrombin (Chrono-log Corporation). Clots were monitored every 15 minutes up to 120 minutes after clot induction. The area of the clot was analyzed in each picture using ImageJ software (Image J 1.52h). At the final time point, the clot exudate was collected and the wet clot weighed.

$\mathrm{FeCl}_{3}$-induced carotid artery injury. These studies were performed essentially as reported previously $(47,48)$. Mice were anesthetized with isoflurane (Abbott Laboratories), and the left carotid artery was exposed. A 0.5- to 1.0-mm strip of Whatman no. 1 filter paper soaked in $5 \% \mathrm{FeCl}_{3}$ solution was applied to the surface of the adventitia for 3 minutes. Carotid blood flow was monitored with a miniature ultrasound flow probe (0.5VB, Transonic Systems) interfaced with a flow meter (model T106, Transonic Systems) and a computerized data acquisition program (WinDaq, DATAQ Instruments). At the end of the 30-minute flow-monitoring period, mice were euthanized by cervical dislocation, and the carotid artery was excised for histological analyses.

Collagen- and epinephrine-induced pulmonary thromboembolism. To induce thromboembolism, mice were anesthetized as described in the tail-bleeding assays, and a mixture of $0.5 \mathrm{mg} / \mathrm{kg}$ equine collagen (Hormon Chemie) and $60 \mu \mathrm{g} / \mathrm{kg}$ epinephrine (MilliporeSigma) was injected into the jugular vein. Most mice died within the first $15 \mathrm{~min}$ utes; otherwise, they were euthanized by cervical dislocation. Histological examination of the lungs was performed to determine whether vessels of the microcirculation were occluded by thrombi consisting of platelet aggregates formed in response to the epinephrine and collagen. When indicated, mice were treated with kinase or phosphatase inhibitors for 1 hour before the induction of pulmonary embolism. These drugs were administered by i.v. injection at the following doses: $0.5 \mathrm{mg} / \mathrm{kg}$ fostriecin, $0.2 \mathrm{mg} / \mathrm{kg}$ dorsomorphin 2- $\mathrm{HCl}$ (compound C analog), 1 mg/kg H89, 10 mg/kg Gö6983, 0.5\% DMSO, or vehicle (10\% PEG400, 0.16\% Tween-80, 1.6\% propylene glycol).

In vitro aggregation studies. For aggregation studies of murine platelets, $500 \mu \mathrm{l}$ washed platelets at $5 \times 10^{8}$ platelets $/ \mathrm{ml}$ were used. Optical platelet aggregation experiments were monitored by a turbidimetric method using an aggregometer (Chrono-log 490 Optical Aggregometer) with continuous stirring at $1,200 \mathrm{rpm}$ at $37^{\circ} \mathrm{C}$. A final concentration of $0.5 \mathrm{UI} / \mathrm{ml}$ thrombin and $5 \mu \mathrm{g} / \mathrm{ml}$ collagen (Chrono-log Corporation) was used as an agonist for the aggregation studies.

Platelet flow cytometric assays. To determine integrin $\alpha \operatorname{IIb} \beta 3$ (GPIIb/IIIa) activation in murine platelets, washed platelets (100 $\mu \mathrm{l}$ of $1 \times 10^{6}$ platelets $/ \mathrm{ml}$ ) were incubated for 15 minutes at room temperature (RT) with rat anti-mouse-PE-CD41a (JON/A) alone (resting) or together with $0.05 \mathrm{IU} / \mathrm{ml}$ thrombin (activated). Reactions were stopped by addition of $400 \mu \mathrm{l}$ PBS, and samples were analyzed within 30 minutes by FACS. The mean fluorescence intensity (MFI) of mutant versus WT platelets was used to measure the activated conformation of mouse integrin $\alpha I I b \beta 3$ (GPIIb/IIIa, CD41/CD61).
Ex vivo fibrinogen binding and fibrinogen uptake assays were performed following the protocol described previously (49), with minor modifications. In brief, washed platelets $\left(100 \mu \mathrm{l}\right.$ of $1 \times 10^{7}$ platelets/ $\mathrm{ml}$ ) were supplemented with $0.15 \mathrm{mg} / \mathrm{ml}$ Alexa Fluor 488-conjugated human fibrinogen (Molecular Probes) and $2 \mathrm{mM} \mathrm{CaCl}_{2}$. Platelets were then incubated for 30 minutes at $37^{\circ} \mathrm{C}$, fixed with $2 \%$ paraformaldehyde, and analyzed by flow cytometry. To study fibrinogen uptake, washed platelets $\left(100 \mu \mathrm{l}\right.$ of $1 \times 10^{7}$ platelets $\left./ \mathrm{ml}\right)$ were incubated with fibrinogen-Alexa Fluor $488(0.15 \mathrm{mg} / \mathrm{ml})$ at $37^{\circ} \mathrm{C}$ for 30 minutes. Platelets were fixed with $2 \%$ paraformaldehyde and analyzed by flow cytometry after addition of $0.04 \%$ trypan blue.

For determination of intracellular F-actin levels, $100 \mu \mathrm{l}$ of $1 \times 10^{7}$ platelets $/ \mathrm{ml}$ were incubated with $0.05 \mathrm{IU} / \mathrm{ml}$ thrombin for 3 minutes and 15 minutes prior to fixation with $2 \%$ paraformaldehyde. Platelets were then permeabilized with $0.05 \%$ Triton X-100 and stained using $2 \mathrm{mM}$ phalloidin-Alexa Fluor 488 for 1 hour at RT. Platelets were washed twice with PBS and then analyzed by flow cytometry.

Platelet surface sialylation and galactose exposure was analyzed by incubation of $100 \mu \mathrm{l}$ washed platelets $\left(1 \times 10^{7}\right.$ platelets $\left./ \mathrm{ml}\right)$ with rat anti-mouse PECy7-CD41 and fluorescein-labeled ricinus communis agglutinin I (FL-RCA I) (used at a final concentration of $0.5 \mu \mathrm{g} / \mathrm{ml}$ ) or fluorescein-labeled Maackia amurensis lectin I (FL-MAL I) (used at a final concentration of $0.5 \mu \mathrm{g} / \mathrm{ml}$ ) (Vector Laboratories) for 45 minutes at RT. Platelets were washed twice with PBS and analyzed by flow cytometry.

For annexin V staining, $1 \times 10^{7}$ platelets were suspended in $100 \mu \mathrm{l}$ $1 \times$ binding buffer (0.01 M HEPES, pH 7.4, $0.14 \mathrm{M} \mathrm{NaCl}, 2.5 \mathrm{mM} \mathrm{CaCl}_{2}$ ) and incubated for 1,3 , or 6 hours at $37^{\circ} \mathrm{C}$. When indicated, platelets were also incubated in the presence of $10 \mu \mathrm{M}$ cytochalasin D (MilliporeSigma) or $5 \mu \mathrm{M}$ jasplakinolide (Tocris). Staining was performed by adding $5 \mu \mathrm{l}$ APC-annexin V (BD Biosciences) and $1 \mu$ FITC-CD41 (clone MWReg30) or FITC-CD9 (clone EM-04) (both from BD Biosciences) for 30 minutes at RT. The reaction was stopped by adding $400 \mu \mathrm{l} 1 \times$ binding buffer and immediately analyzed by flow cytometry.

In all the assays described above, 10,000 platelet-gate events were collected per experiment in a BD FACSCanto II cytometer. Data were analyzed with FlowJo software, version 8.8.7, and the MFI was use to evaluate fibrinogen binding, fibrinogen uptake, F-actin content, sialylation, and annexin $\mathrm{V}$ binding, respectively.

Transmission electron microscopy. Resting and thrombin (0.05 $\mathrm{IU} / \mathrm{ml}, 15 \mathrm{~min}$ ) activated platelets were fixed for 3 hours at RT in 3\% glutaraldehyde (vol/vol) in $0.4 \mathrm{M} \mathrm{N}$-2-hydroxyethylpiperazine- $N^{\prime}-2$ ethanesulfonic acid buffer, $\mathrm{pH}$ 7.4, washed, fixed again in aqueous $1 \%$ (wt/vol) osmium tetroxide, and then embedded in epon. Electron microscopic analysis was performed with a JEOL 1230 transmission electron microscope, at $80 \mathrm{kV}$, on ultrathin sections of $60-\mathrm{nm}$ for biochemical assays.

Analysis of MEFs. MEFs were isolated from E13.5 embryos and analyzed using routine cell-cycle protocols (12). For flow cytometric analysis, cells were washed in PBS and fixed in ice-cold 70\% ethanol. For identification of mitotic cells, cells were blocked using 3\% BSA in PBS for 1 hour, followed by addition of MPM2 antibody (MilliporeSigma, 1:200) in blocking solution. Antibodies were detected with Alexa Fluor 594 (1:1,000), and DAPI was used to stain the nuclei. Cell-cycle profiles were determined using a FACSCanto II Flow Cytometry System (BD Biosciences). Data were analyzed using FlowJo software, version 7.5.

Biochemical assays. Two hundred fifty microliters of washed platelets at $5 \times 10^{8}$ platelets $/ \mathrm{ml}$ were supplemented with $0.05 \mathrm{IU} / \mathrm{ml}$ thrombin 
(Chrono-log Corporation) and incubated at $37^{\circ} \mathrm{C}$ for different durations. Then, $250 \mu \mathrm{l} 2 \times$ RIPA lysis buffer (100 mM Tris- $\mathrm{HCl}$, pH 8.0, 0.2\% SDS, $2 \% \mathrm{NP}-40,1 \%$ sodium deoxycholate) supplemented with a mixture of protease and phosphatase inhibitors (PhosSTOP and Complete Protease Inhibitor Cocktail, Roche Applied Science) were added. The homogenate was incubated in ice for 30 minutes and centrifuged at 13,000 $g$ for 15 minutes at $4^{\circ} \mathrm{C}$, for collection of the supernatant. Protein lysates from MEFs were prepared as described previously (11). Total protein was quantified by selective colorimetric detection using a commercial bicinchoninic acid kit (BCA Protein Assay Reagent Kit, Pierce, Thermo Fisher Scientific), and samples were boiled in loading buffer $(70 \%$ v/v] $0.5 \mathrm{M}$ Tris- $\mathrm{HCl} 0.4 \%$ [w/v] sodium dodecil sulphate, $\mathrm{pH} 6.8,30 \%$ [v/v] glycerol, 10\% [w/v] SDS, 9.3\% [w/v] dithioteitol, 0.012\% [w/v] bromophenol blue, and $10 \%$ [v/v] $\beta$-mercaptoethanol) at $98^{\circ} \mathrm{C}$ for 10 minutes.

For Western blot analyses, $50 \mu \mathrm{g}$ total protein extract from murine platelets was analyzed by SDS-PAGE (4\%-15\% Criterion TGX Precast Midi Protein Gel, Bio-Rad) before transfer to a nitrocellulose membrane. Membranes were blocked for 1 hour at room temperature with $5 \%(\mathrm{w} / \mathrm{v}$ ) nonfat milk in TBS-T (50 mM Tris-Cl, $100 \mathrm{mM} \mathrm{NaCl}, 0.1 \%$ Tween-20, pH 7.4) and incubated overnight at $4^{\circ} \mathrm{C}$ with the indicated antibodies (Supplemental Table 8). All membranes were rinsed 3 times with TBS-T and incubated with secondary antibodies conjugated with HRP. Protein detection was done using the ECL Advance Western Blotting Detection System (Amersham Biosciences) and x-ray film exposure, following the recommendations of the manufacturer.

For in vitro kinase assays, HEK293 cells (American Type Culture Collection [ATCC]) were transiently transfected with V5-tagged Mastl mutants. Cells were lysed in ELB buffer (50 mM HEPES, pH 7.5, 150 $\mathrm{mM} \mathrm{NaCl}, 5 \mathrm{mM}$ EDTA, 1\% NP-40) in the presence of protease and phosphatase inhibitors. Exogenous Mastl was immunoprecipitated with an anti-V5 antibody (Invitrogen, Thermo Fisher Scientific), and immunocomplexes were incubated in kinase buffer (20 mM HEPES, $\mathrm{pH} 7.5,10 \mathrm{mM} \mathrm{MgCl} 2,1 \mathrm{mM}$ DTT) in the presence of $50 \mu \mathrm{M}$ ATP, $2 \mu \mathrm{Ci}$ $32 \mathrm{P}-\gamma$-ATP, and $2 \mu \mathrm{g}$ MBP as a substrate, over a 30-minute period at $30^{\circ} \mathrm{C}$. Samples were analyzed by SDS-PAGE and transferred to a nitrocellulose membrane, and images were obtained by autoradiography. Quantifications were performed using a PhosphorImager (Bio-Rad). For measurement of the activity of Mastl in MEFs, cells were lysed in ELB buffer, and endogenous Mastl was immunoprecipitated with an anti-Mastl antibody (Abgent). Kinase assays were performed following the same protocol as that described above.

Uncropped scans of all gels shown in the figures are included in Supplemental Figure 7.

Phosphoproteomics analysis. Cells were lysed using $7 \mathrm{M}$ urea and $2 \mathrm{M}$ thiourea in $100 \mathrm{mM}$ HEPES, $\mathrm{pH} 7.5$, supplemented with 1:1,000 (v/v) benzonase (Novagen) and 1:100 (v/v) Halt phosphatase and protease inhibitor cocktail $100 \times$ (Thermo Fisher Scientific). The protein concentration was determined using the Pierce $660 \mathrm{~nm}$ Protein Assay (Bio-Rad), with BSA as the standard. Then, samples $(160 \mu \mathrm{g})$ were digested by means of the standard FASP protocol. Briefly, proteins were reduced (15 $\mathrm{mM}$ TCEP, $30 \mathrm{~min}$ at RT), alkylated $(50 \mathrm{mM}$ CAA, 20 min in the dark at RT), and sequentially digested with Lys-C (Wako) (protein/enzyme ratio of 1:50, overnight at RT) and trypsin (Promega) (protein/enzyme ratio of $1: 100,6 \mathrm{~h}$ at $37^{\circ} \mathrm{C}$ ). Samples were labeled using iTRAQ Reagent 8-Plex (Sciex) following the manufacturer's instructions. Samples were mixed at 1:1 ratios based on the total amount of peptide, which was determined from an aliquot by comparing overall signal intensities on a regular liquid chromatography tandem mass spectrometry (LC-MS/MS) run. The final mixture was finally desalted using a Sep-Pak C18 cartridge (Waters) and dried.

Phosphopeptides were enriched using homemade $\mathrm{TiO}_{2}$ microcolumns. Briefly, peptides were resuspended in $6 \%$ trifluoroacetic acid (TFA) and $80 \% \mathrm{CH}_{3} \mathrm{CN}$ and incubated for 20 minutes with $\mathrm{TiO}_{2}$ beads (10- $\mu \mathrm{m}$ particle size) (GL Sciences) using a sample/ $\mathrm{TiO}_{2}$ ratio of 1:2. Prior to incubation, $\mathrm{TiO} 2$ beads were preconditioned with a solution of 20 $\mathrm{mg} / \mathrm{ml} \mathrm{DHB}$ in $80 \% \mathrm{CH}_{3} \mathrm{CN}$ and 6\% TFA for 20 minutes. Then, beads were sequentially washed with $100 \mu$ of $6 \%$ TFA and $10 \% \mathrm{CH}_{3} \mathrm{CN}, 100$ $\mu \mathrm{l}$ of $6 \%$ TFA and $100 \mu \mathrm{l}$ of $40 \% \mathrm{CH}_{3} \mathrm{CN}$, and $6 \%$ TFA and $60 \% \mathrm{CH}_{3} \mathrm{CN}$. Finally, phosphopeptides were eluted first with $20 \mu \mathrm{l}$ of $5 \% \mathrm{NH}_{4} \mathrm{OH}$ and then with $20 \mu \mathrm{l} 5 \% \mathrm{NH}_{4} \mathrm{OH}$ in $10 \% \mathrm{CH}_{3} \mathrm{CN}$ in the same vial.

Phosphopeptides were fractionated offline by means of a high $\mathrm{pH}$ reverse-phase microcolumn. Samples were dissolved in phase A (20 $\mathrm{mM} \mathrm{NH}_{4} \mathrm{OH}$ ) and loaded into a tip containing 5 discs of $\mathrm{C} 18$, and the flow-through was collected into a vial. Peptides were sequentially eluted by increasing the percentage of buffer $\mathrm{B}\left(2 \mathrm{mM} \mathrm{NH} \mathrm{min}_{3} \mathrm{CH}_{3} \mathrm{CN}\right)$ (i.e., $4 \%, 8 \%, 12 \%, 20 \%, 60 \%$, and $80 \%$ ). The last 3 fractions were pooled together.

LC-MS/MS was done by coupling a nanoLC-Ultra 1D+ System (Eksigent) to an Impact Mass Spectrometer (Bruker) via a Captivespray Source (Bruker) supplemented with a nanobooster operated at 0.2 bar/ minute with isopropanol as a dopant. Peptides were loaded into a trap column (NS-MP-10 BioSphere C18 $5 \mu \mathrm{m}, 20$-mm length, Nanoseparations) for 10 minutes at a flow rate of $2.5 \mu \mathrm{l} /$ minute in $0.1 \%$ formic acid (FA). Then, peptides were transferred to an analytical column (ReproSil Pur C18-AQ2.4 $\mu \mathrm{m}, 500$-mm length and 0.075-mm ID) and separated using a 95-minute gradient (buffer A: $4 \%$ acetonitrile [ACN], 0.1\% FA; buffer B: $100 \% \mathrm{ACN}, 0.1 \% \mathrm{FA}$ ) at a flow rate of $250 \mathrm{nl} /$ minute. The gradients used were: 0-2 minutes, $6 \%$ B; $2-80$ minutes, $30 \%$ B; 80.5-87.5 minutes, $98 \%$ B; $88-95$ minutes, $2 \%$ B. The peptides were electrosprayed $(1.35 \mathrm{kV})$ into the mass spectrometer with a heated capillary temperature of $180^{\circ} \mathrm{C}$. The mass spectrometer was operated in the data-dependent mode, with an automatic switch between MS (80-1,600 m/z) and MS/MS (80-1,600 $\mathrm{m} / z$ ) scans using a top-30 method (threshold signal $\geq 500$ counts, $z \geq 2$ and $m / z \geq 350$ ). An active exclusion of 30 seconds was used. The precursor intensities were reevaluated in the MS scan (n) regarding their values in the previous MS scan (n minus 1 ). Any $m / z$ intensity exceeding 5 times the measured value in the preceding MS scan was reconsidered for MS/ MS. Peptides were isolated using a 2 Th window and fragmented using collision-induced dissociation (CID), with a collision energy of 23 to 56 $\mathrm{eV}$ as a function of the $m / z$ value.

For data analysis, raw files were processed with MaxQuant, version 1.5.8.3, using the standard settings against a mouse protein database (UniProtKB/Swiss-Prot and TrEMBL, August 2016; 43,965 sequences) supplemented with contaminants. Carbamidomethylation of cysteines was set as a fixed modification, whereas oxidation of methionines, protein N-terminal acetylation, and phosphorylation of serines, threonines, and tyrosines were set as variable modifications. The minimal peptide length was set to 7 amino acids, and a maximum of 2 tryptic missed cleavages were allowed. Results were filtered at a FDR of 0.01 (peptide and protein levels). For the phosphoproteome, the "phospho(STY)sites.txt" file was loaded into Perseus, version 1.5.1.6, for further analysis. Phosphosites with a probability above 0.75 and a score difference below 5 were considered localized (class I). Phosphosites with a $\log _{2}$ FC ratio above 0.75 or less than or equal 
to 0.75 were considered regulated. Overrepresentation of functional terms was performed with the STRINGdb (50), using the platelets proteome (51) as the background data set. A Fisher's exact test with multiple tests correction was used, and only terms with a FDR below $5 \%$ were considered statistically significant.

The MS proteomics data were deposited in the ProteomeXchange Consortium database via the PRoteomics IDEntifications (PRIDE) partner repository (data set identifier: PXD009398).

Platelet spreading assays. Spreading assays were performed as described previously (46). In brief, Lab-Tek Chamber Slides (Nunc) were coated overnight at $4^{\circ} \mathrm{C}$ with $100 \mu \mathrm{g} / \mathrm{ml}$ human fibrinogen (MilliporeSigma) in PBS, pH 8.0. Next, they were washed with PBS and blocked with $5 \mathrm{mg} / \mathrm{ml}$ heat-denatured BSA for 2 hours at RT and then washed again. Platelets at $1 \times 10^{8}$ platelets $/ \mathrm{ml}$ were incubated on the fibrinogen-coated chambers and allowed to spread for $5,15,30$, and 60 minutes at $37^{\circ} \mathrm{C}$ in the presence of $0.05 \mathrm{IU} / \mathrm{ml}$ thrombin. For actin inhibitors, platelets were allowed to adhere for 5 minutes, and then cytochalasin D or jasplakalodine was added at a final concentration of $10 \mu \mathrm{M}$ and $5 \mu \mathrm{M}$, respectively, and allowed to spread for $15 \mathrm{~min}-$ utes. After that, chambers were washed, and adhered platelets were fixed with $4 \%$ of paraformaldehyde (PFA) for 10 minutes. After washing, chambers were incubated with $100 \mathrm{mM}$ glycine for 5 minutes and washed. Then, adhered platelets were permeabilized with $0.2 \%$ Triton X-100 for 5 minutes, washed, and blocked with 10\% normal goat serum (MilliporeSigma) for 30 minutes. Platelets were incubated with an anti- $\alpha$-tubulin primary antibody, followed by the Alexa Fluor 488 goat anti-mouse secondary antibody. Phalloidin-Alexa Fluor 564 was used to stain F-actin. Images were acquired with a Leica TCS SP5 WLL confocal laser microscope using a HCX PLAN APO CS 63x/1.4 Oil Immersion or HCX PLAN APO CS $100 \times / 1.4$ Oil Immersion. For platelet morphology quantification, at least 150 platelets per sample were measured using Fiji software.

Statistics. Statistical analyses were performed using GraphPad Prism software (GraphPad Software). Unless stated otherwise, all statistical tests of comparative data were done using a Mann-Whitney $U$ test or a 2-sided, unpaired Student's $t$ test when Welch's correction when needed. For survival analysis, a log-rank (Mantel-Cox) test with Bonferroni's correction was applied. Data are expressed as the mean of at least 3 independent experiments \pm SEM, with a $P$ value of less than 0.05 considered statistically significant.
Study approval. All animal protocols were approved by the committee for animal care and research of the Instituto de Salud Carlos III/Comunidad de Madrid (Madrid, Spain).

\section{Author contributions}

$\mathrm{BH}$ performed most platelet assays in vitro and in vivo with the help of AEB. MT generated the mouse models, contributed to some platelet assays, and characterized hematopoietic tissues and megakaryocytes with the help of DP and M. Maroto. RSM contributed to the generation of the knockin model. BSC and MT performed the assays in MEFs, with the help of MAF. PXE and JM performed the phosphoproteomic analyses. LM helped with the cytometric studies. PGDF supervised the thrombosis models and contributed to the analysis of data. M. Malumbres designed and supervised the project and wrote the manuscript with the help of BH and MT.

\section{Acknowledgments}

We thank Peter Storz (Mayo Clinic, Jacksonville, Florida, USA) for sharing reagents and Sheila Rueda (Centro Nacional de Investigaciones Oncológicas [CNIO], Madrid, Spain) for her support with the management of the mouse colony. BH and RSM were supported by the Juan de la Cierva Programme of the Spanish Ministry of Economy and Competitiveness (MINECO). MT was supported by the Foundation La Caixa. AEB was supported by the Programa de Empleo Juvenil, Comunidad de Madrid. MAF received a young investigator grant from MINECO (SAF2014-60442-JIN, cofinanced by FEDER funds). PGDF was supported by the Fundació la Marató de TV3 (projects 080121 and 20153031). JM was supported by the Ramon y Cajal Programme (MINECO; RYC2012-10651). The laboratory of MM is supported by grants from MINECO (SAF2015-69920-R); the Programa iLUNG from the Comunidad de Madrid (B2017/BMD-3884); and Worldwide Cancer Research (15-0278). CNIO is a Severo Ochoa Center of Excellence (MINECO award SEV-2015-0510).

Address correspondence to: Marcos Malumbres, Centro Nacional de Investigaciones Oncológicas (CNIO), Melchor Fernández Almagro 3, E-28029 Madrid, Spain. Phone: 34.91.732.8000; Email:malumbres@cnio.es.
1. Glover DM. The overlooked greatwall: a new perspective on mitotic control. Open Biol. 2012;2(3):120023.

2. Lorca T, Castro A. The Greatwall kinase: a new pathway in the control of the cell cycle. Oncogene. 2013;32(5):537-543.

3. White-Cooper H, Carmena M, Gonzalez C, Glover DM. Mutations in new cell cycle genes that fail to complement a multiply mutant third chromosome of Drosophila. Genetics. 1996;144(3):1097-1111.

4. Yu J, et al. Greatwall kinase: a nuclear protein required for proper chromosome condensation and mitotic progression in Drosophila. J Cell Biol. 2004;164(4):487-492.

5. Archambault V, Zhao X, White-Cooper H, Carpenter AT, Glover DM. Mutations in Drosophila Greatwall/Scant reveal its roles in mitosis and meiosis and interdependence with Polo kinase.
PLoS Genet. 2007;3(11):e200.

6. Gharbi-Ayachi A, et al. The substrate of Greatwall kinase, Arpp19, controls mitosis by inhibiting protein phosphatase 2A. Science. 2010;330(6011):1673-1677.

7. Mochida S, Maslen SL, Skehel M, Hunt T. Greatwall phosphorylates an inhibitor of protein phosphatase 2A that is essential for mitosis. Science. 2010;330(6011):1670-1673.

8. Vigneron S, Brioudes E, Burgess A, Labbé JC, Lorca T, Castro A. Greatwall maintains mitosis through regulation of PP2A. EMBO J. 2009;28(18):2786-2793.

9. Burgess A, Vigneron S, Brioudes E, Labbé JC, Lorca T, Castro A. Loss of human Greatwall results in $\mathrm{G} 2$ arrest and multiple mitotic defects due to deregulation of the cyclin B-Cdc2/ PP2A balance. Proc Natl Acad Sci US A.
2010;107(28):12564-12569.

10. Voets E, Wolthuis RM. MASTL is the human orthologue of Greatwall kinase that facilitates mitotic entry, anaphase and cytokinesis. Cell Cycle. 2010;9(17):3591-3601.

11. Manchado E, et al. Targeting mitotic exit leads to tumor regression in vivo: Modulation by Cdk1, Mastl, and the PP2A/B55 $\alpha, \delta$ phosphatase. Cancer Cell. 2010;18(6):641-654.

12. Álvarez-Fernández M, et al. Greatwall is essential to prevent mitotic collapse after nuclear envelope breakdown in mammals. Proc Natl Acad Sci U S A. 2013;110(43):17374-17379.

13. Alvarez-Fernández M, Malumbres M. Preparing a cell for nuclear envelope breakdown: Spatio-temporal control of phosphorylation during mitotic entry. Bioessays. 2014;36(8):757-765.

14. Gandhi MJ, Cummings CL, Drachman JG. 
FLJ14813 missense mutation: a candidate for autosomal dominant thrombocytopenia on human chromosome 10. Hum Hered. 2003;55(1):66-70.

15. Bithell TC, Didisheim P, Cartwright GE, Wintrobe MM. Thrombocytopenia inherited as an autosomal dominant trait. Blood. 1965;25:231-240.

16. Drachman JG, Jarvik GP, Mehaffey MG. Autosomal dominant thrombocytopenia: incomplete megakaryocyte differentiation and linkage to human chromosome 10. Blood. 2000;96(1):118-125.

17. Pippucci T, et al. Mutations in the 5' UTR of ANKRD26, the ankirin repeat domain 26 gene, cause an autosomal-dominant form of inherited thrombocytopenia, THC2. Am J Hum Genet. 2011;88(1):115-120.

18. Noris P, et al. Mutations in ANKRD26 are responsible for a frequent form of inherited thrombocytopenia: analysis of 78 patients from 21 families. Blood. 2011;117(24):6673-6680.

19. Di Paola J, Johnson J. Thrombocytopenias due to gray platelet syndrome or THC2 mutations. Semin Thromb Hemost. 2011;37(6):690-697.

20. Tiedt R, Schomber T, Hao-Shen H, Skoda RC. Pf4-Cre transgenic mice allow the generation of lineage-restricted gene knockouts for studying megakaryocyte and platelet function in vivo. Blood. 2007;109(4):1503-1506.

21. Yano Y, et al. Cytoskeletal reorganization of human platelets induced by the protein phosphatase 1/2 A inhibitors okadaic acid and calyculin A. Biochem J. 1995;307(Pt 2):439-449.

22. Castilho PV, Williams BC, Mochida S, Zhao Y, Goldberg ML. The M phase kinase Greatwall (Gwl) promotes inactivation of PP2A/B55delta, a phosphatase directed against CDK phosphosites. Mol Biol Cell. 2009;20(22):4777-4789.

23. Rogers S, McCloy R, Watkins DN, Burgess A. Mechanisms regulating phosphatase specificity and the removal of individual phosphorylation sites during mitotic exit. Bioessays. 2016;38 Suppl 1:S24-S32.

24. Gushiken FC, et al. Protein phosphatase 2A negatively regulates integrin alpha(IIb)beta(3) signaling. J Biol Chem. 2008;283(19):12862-12869.

25. Pula G, Schuh K, Nakayama K, Nakayama KI, Walter U, Poole AW. PKCdelta regulates collagen-induced platelet aggregation through inhibition of VASP-mediated filopodia formation. Blood. 2006;108(13):4035-4044.

26. Wentworth JK, Pula G, Poole AW. Vasodilator-stimulated phosphoprotein (VASP) is phosphorylated on Ser157 by protein kinase
C-dependent and -independent mechanisms in thrombin-stimulated human platelets. Biochem J. 2006;393(Pt 2):555-564.

27. Döppler H, Storz P. Regulation of VASP by phosphorylation: consequences for cell migration. Cell Adh Migr. 2013;7(6):482-486.

28. Butt E, et al. cAMP- and cGMP-dependent protein kinase phosphorylation sites of the focal adhesion vasodilator-stimulated phosphoprotein (VASP) in vitro and in intact human platelets. J Biol Chem. 1994;269(20):14509-14517.

29. Onselaer $\mathrm{MB}$, et al. The $\mathrm{Ca}(2+)$ /calmodulindependent kinase kinase $\beta$-AMP-activated protein kinase- $\alpha 1$ pathway regulates phosphorylation of cytoskeletal targets in thrombin-stimulated human platelets. J Thromb Haemost. 2014;12(6):973-986.

30. Chica N, Rozalén AE, Pérez-Hidalgo L, Rubio A, Novak B, Moreno S. Nutritional Control of Cell Size by the Greatwall-Endosulfine-PP2A-B55 Pathway. Curr Biol. 2016;26(3):319-330.

31. Moreno-Torres M, Jaquenoud M, De Virgilio C. TORC1 controls G1-S cell cycle transition in yeast via Mpk1 and the greatwall kinase pathway. Nat Commun. 2015;6:8256.

32. Johnson HJ, et al. In vivo inactivation of MASTL kinase results in thrombocytopenia. Exp Hematol. 2009;37(8):901-908.

33. Trakala $\mathrm{M}$, et al. Functional reprogramming of polyploidization in megakaryocytes. Dev Cell. 2015;32(2):155-167.

34. Bluteau D, et al. Thrombocytopenia-associated mutations in the ANKRD26 regulatory region induce MAPK hyperactivation. JClin Invest. 2014;124(2):580-591.

35. Toyoda H, et al. Differential association of protein Ser/Thr phosphatase types 1 and 2A with the cytoskeleton upon platelet activation. Thromb Haemost. 1996;76(6):1053-1062.

36. Moscardó A, Santos MT, Latorre A, Madrid I, Vallés J. Serine/threonine phosphatases regulate platelet $\alpha \mathrm{IIb} \beta 3$ integrin receptor outside-in signaling mechanisms and clot retraction. Life Sci. 2013;93(20):707-713.

37. Mayanglambam A, Bhavanasi D, Vijayan KV, Kunapuli SP. Differential dephosphorylation of the protein kinase C-zeta (PKC) $)$ in an integrin $\alpha I I b \beta 3$-dependent manner in platelets. Biochem Pharmacol. 2011;82(5):505-513.

38. Abel K, Mieskes G, Walter U. Dephosphorylation of the focal adhesion protein VASP in vitro and in intact human platelets. FEBS Lett.
1995;370(3):184-188.

39. Tournebize R, Andersen SS, Verde F, Dorée M, Karsenti E, Hyman AA. Distinct roles of PP1 and PP2A-like phosphatases in control of microtubule dynamics during mitosis. $E M B O J$. 1997;16(18):5537-5549.

40. Vigneron S, et al. Characterization of the mechanisms controlling Greatwall activity. Mol Cell Biol. 2011;31(11):2262-2275.

41. Blake-Hodek KA, et al. Determinants for activation of the atypical AGC kinase Greatwall during M phase entry. Mol Cell Biol. 2012;32(8):1337-1353.

42. VonDerLinden D, Ma X, Sandberg EM, Gernert K, Bernstein KE, Sayeski PP. Mutation of glutamic acid residue 1046 abolishes Jak2 tyrosine kinase activity. Mol Cell Biochem. 2002;241(1-2):87-94.

43. Álvarez-Fernández M, et al. Therapeutic relevance of the PP2A-B55 inhibitory kinase MASTL/ Greatwall in breast cancer. Cell Death Differ. 2018;25(5):828-840.

44. Cazenave JP, Ohlmann P, Cassel D, Eckly A, Hechler B, Gachet C. Preparation of washed platelet suspensions from human and rodent blood. Methods Mol Biol. 2004;272:13-28.

45. Akbar H, et al. Gene targeting implicates Cdc42 GTPase in GPVI and non-GPVI mediated platelet filopodia formation, secretion and aggregation. PLoS One. 2011;6(7):e22117.

46. Prévost N, Kato H, Bodin L, Shattil SJ. Platelet integrin adhesive functions and signaling. Meth Enzymol. 2007;426:103-115.

47. Farrehi PM, Ozaki CK, Carmeliet P, Fay WP. Regulation of arterial thrombolysis by plasminogen activator inhibitor-1 in mice. Circulation. 1998;97(10):1002-1008.

48. Konstantinides S, Schäfer K, Thinnes T, Loskutoff DJ. Plasminogen activator inhibitor-1 and its cofactor vitronectin stabilize arterial thrombi after vascular injury in mice. Circulation. 2001;103(4):576-583.

49. Huang Y, et al. Arf6 controls platelet spreading and clot retraction via integrin $\alpha \mathrm{IIb} \beta 3$ trafficking. Blood. 2016;127(11):1459-1467.

50. Szklarczyk D, et al. The STRING database in 2017: quality-controlled protein-protein association networks, made broadly accessible. Nucleic Acids Res. 2017;45(D1):D362-D368.

51. Zeiler M, Moser M, Mann M. Copy number analysis of the murine platelet proteome spanning the complete abundance range. Mol Cell Proteomics. 2014;13(12):3435-3445. 